\title{
Fatores que afetam as características morfogênicas e estruturais de plantas
}

\section{forrageiras}

\author{
Factors affecting the morphogenic and structural characteristics of forage plants \\ Factores que afectan las características morfogénicas y estructurales de las plantas forrajeras
}

Recebido: 17/05/2021 | Revisado: 27/05/2021 | Aceito: 31/05/2021 | Publicado: 13/06/2021

Natan Teles Cruz

ORCID: https://orcid.org/0000-0001-8164-0429 Universidade Estadual do Sudoeste da Bahia, Brasil E-mail: teles.nc@gmail.com

Aureliano José Vieira Pires

ORCID: https://orcid.org/0000-0002-4015-3445 Universidade Estadual do Sudoeste da Bahia, Brasil E-mail: aurelianojvp@uesb.edu.br

Daniela Deitos Fries

ORCID: https://orcid.org/0000-0002-3827-6905 Universidade Estadual do Sudoeste da Bahia, Brasil E-mail: friesdd@hotmail.com

Renata Rodrigues Jardim

ORCID: https://orcid.org/0000-0002-4022-5541 Universidade Estadual do Sudoeste da Bahia, Brasil E-mail: renatajardimagro@ @otmail.com

Braulio Maia de Lana Sousa

ORCID: https://orcid.org/0000-0001-5587-8177 Universidade Federal de Sergipe, Brasil

E-mail: bmaiasousa@yahoo.com.br

Daniel Lucas Santos Dias

ORCID: https://orcid.org/0000-0003-2243-4400

Universidade Estadual de Feira de Santana, Brasil E-mail: dlsd_@hotmail.com

Paulo Bonomo

ORCID: https://orcid.org/0000-0002-1892-0185 Universidade Estadual do Sudoeste da Bahia, Brasil E-mail: bonomopaulo@gmail.com

Bárbara Louise Pacheco Ramos ORCID: https://orcid.org/0000-0001-5055-7120 Universidade Estadual do Sudoeste da Bahia, Brasil E-mail: agro.barbara@ outlook.com

Marina Raíssa Silva Vieira do Sacramento

ORCID: https://orcid.org/0000-0001-5047-3832 Universidade Estadual do Sudoeste da Bahia, Brasil E-mail: marinasacramento.aju@gmail.com

\begin{abstract}
Resumo
Objetivou-se com esta revisão abordar os principais fatores que afetam as características morfogênicas e estruturais de plantas forrageiras. Dentro do sistema agropecuário brasileiro, predomina-se a criação de animais a pasto. Devido às condições favoráveis do território nacional, é possível produzir diversas espécies de plantas forrageiras. Neste sentido, o entendimento do comportamento do ecossistema de forragem frente às variações dos recursos naturais se torna uma ferramenta capaz de auxiliar na elaboração de metas de manejo sustentáveis. A morfogênese é utilizada para mensurar o aparecimento e expansão dos órgãos vegetais através do fluxo de tecidos que ocorrem dentro do dossel forrageiro. De maneira geral, as características estruturais de um dossel forrageiro dependem das características morfogênicas da espécie, que são determinadas geneticamente. No entanto, essas caraterísticas sofrem influência direta de fatores abióticos e bióticos que alteram o padrão de crescimento dessas plantas. Ademais, através da avaliação dos processos morfogenéticos envolvidos no ecossistema de pastagem, é possível elaborar metas de manejo sustentável do dossel forrageiro, contribuindo para elevar a produtividade dos sistemas agropecuários do Brasil.
\end{abstract}

Palavras-chave: Gramíneas; Morfogênese; Forragem; Tropical. 


\begin{abstract}
The objective of this review was to address the main factors that affect the morphogenic and structural characteristics of forage plants. Within the Brazilian agricultural system, there is a predominance of livestock on pasture. Due to the favorable conditions of the national territory, it is possible to produce several species of forage plants. In this sense, understanding the behavior of the forage ecosystem in the face of variations in natural resources becomes a tool capable of assisting in the development of sustainable management goals. Morphogenesis is used to measure the appearance and expansion of plant organs through the flow of tissues that occur within the forage canopy. In general, the structural characteristics of a forage canopy, depends on the morphogenic characteristics of the species, which are genetically determined. However, these characteristics are directly influenced by abiotic and biotic factors that alter the growth pattern of these plants. Furthermore, through the evaluation of the morphogenetic processes involved in the pasture ecosystem, it is possible to develop goals for the sustainable management of the forage canopy, contributing to increase the productivity of agricultural systems in Brazil.
\end{abstract}

Keywords: Grasses; Morphogenesis; Forage; Tropical.

\title{
Resumen
}

El objetivo de esta revisión fue abordar los principales factores que inciden en las características morfogénicas y estructurales de las plantas forrajeras. Dentro del sistema agrícola brasileño, hay un predominio de la ganadería en el pasto. Debido a las favorables condiciones del territorio nacional, es posible producir varias especies de plantas forrajeras. En este sentido, comprender el comportamiento del ecosistema forrajero ante variaciones en los recursos naturales se convierte en una herramienta capaz de ayudar en el desarrollo de metas de manejo sustentable. La morfogénesis se usa para medir la apariencia y expansión de los órganos de las plantas a través del flujo de tejidos que ocurren dentro del dosel del forraje. En general, las características estructurales de un dosel forrajero dependen de las características morfogénicas de la especie, las cuales están determinadas genéticamente. Sin embargo, estas características están directamente influenciadas por factores abióticos y bióticos que alteran el patrón de crecimiento de estas plantas. Además, a través de la evaluación de los procesos morfogenéticos involucrados en el ecosistema de pastos, es posible desarrollar metas para el manejo sustentable del dosel forrajero, contribuyendo a incrementar la productividad de los sistemas agrícolas en Brasil.

Palabras clave: Pastos, Morfogénesis, Forraje, Tropical.

\section{Introdução}

O cenário agropecuário do Brasil destaca-se por seu grande potencial de produção animal a pasto, devido à sua extensão continental e condição climática que favorece o crescimento de diversas espécies pelo país. Desta maneira, o conhecimento das características ecofisiológicas envolvidas no sistema de pastagem tem a capacidade de auxiliar na elaboração de estratégias de manejo sustentáveis (Silva et al., 2015).

Dentro do ecossistema de forragem, existe um fluxo de massa e energia que controla os processos fisiológicos do dossel forrageiro, no qual qualquer alteração nos fatores de crescimento resulta na modificação de sua estrutura (Gastal e Lemaire, 2015). Neste sentido, a descrição do processo de morfogênese tem papel crucial no entendimento do crescimento de uma planta forrageira.

De maneira geral, a morfogênese é definida como a dinâmica de geração e expansão dos órgãos da planta no espaçotempo, podendo ser descrita através das avaliações das taxas de aparecimento e alongamento de folhas, taxa de alongamento de colmos e duração de vida das folhas (Pereira, 2013). Adicionalmente, de acordo com Rodrigues et al. (2012), por meio do estudo da morfogênese é possível descrever a dinâmica de crescimento, adaptação ecológica e o acúmulo dos componentes morfológicos de uma espécie forrageira. Assim, as avaliações dessas características vêm contribuindo para que o gerenciamento dos dosséis forrageiros seja feito de forma adequada, respeitando os limites fisiológicos de cada espécie forrageira.

Segundo Braz et al. (2017), as características estruturais do dossel forrageiro são resultado do desenvolvimento morfogênico da espécie, que apesar de serem definidas geneticamente, são fortemente influenciadas por fatores como luminosidade, temperatura, disponibilidade hídrica e fertilidade do solo. Ademais, além dos atributos químicos do solo, sua composição física deve ser levada em consideração, uma vez que afeta o processo de morfogênese e crescimento de plantas 
forrageiras (Bezerra et al., 2020). Assim, todos os fatores que estão envolvidos no ecossistema de pastagem (solo-plantaanimal) possuem forte ligação com as modificações morfogênicas das espécies forrageiras.

Por meio do gerenciamento do manejo das pastagens, é possível modificar os padrões de crescimento da planta. Fatores como redução da luminosidade no dossel forrageiro através do crescimento do dossel em monocultivo ou consórcio, disponibilidade hídrica e de nutrientes, e manejo do pastejo são capazes de alterar a composição do dossel forrageiro e comprometer a produtividade do sistema (Braz et al., 2017; Lopes et al., 2017). Nesse sentido, através da morfogênese de uma determinada espécie, é possível estimar sua produtividade e qualidade nutricional dentro do dossel forrageiro e, assim, elaborar planos de utilização que maximizem a utilização da forragem com maior qualidade possível (Sbrissia et al., 2018)

A compreensão da morfogênese apresenta-se como uma ferramenta capaz de entender o fluxo de biomassa dentro do dossel forrageiro em resposta ao manejo adotado. Ademais, Souza et al. (2020) relatam que, através da morfogênese, é possível conhecer o comportamento e o limite fisiológico de cada espécie e cultivar por meio dos recursos de crescimento disponíveis e, assim, elaborar recomendações de manejo condizentes com a necessidade da espécie presente no sistema.

Desta forma, objetivou-se com esta revisão abordar sobre os principais fatores que afetam as características morfogênicas e estruturais de plantas forrageiras.

\section{Metodologia}

Consiste em uma revisão bibliográfica com base em artigos científicos publicados em periódicos nacionais e internacionais acerca dos fatores que afetam as características morfogênicas e estruturais de plantas forrageiras. Assim, de acordo com Pereira et al. (2018), trata-se de uma revisão exploratória de natureza qualitativa, visto que as produções bibliográficas sobre este tema específico foram analisadas evidenciando suas ideias e subtemas que possuem maior ou menor relevância dentro da literatura selecionada. Foi estabelecido como critério de inclusão os artigos publicados na integra, disponíveis nos idiomas português, inglês e espanhol que avaliaram e descreveram como os fatores envolvidos no ecossistema de pastagem afetam as características morfogênicas e estruturais do dossel forrageiro. Artigos não relacionados ao tema ou que não forneceram informações relevantes para a elaboração dessa revisão, foram excluídos.

\section{Desenvolvimento}

\subsection{Fluxos de tecidos no ecossistema de pastagem}

O ecossistema de pastagem é um sistema complexo formado pela associação de componentes bióticos e abióticos que interagem entre si. Neste sentido, levar em consideração os fatores envolvidos no sistema (desde solo ao clima do local e espécie animal presente), é essencial para a definição de práticas de manejo sustentáveis (Silva et al., 2015). Adicionalmente, um dos grandes entraves para a produção animal brasileira é a manutenção e produtividade das pastagens forrageiras.

Isto acontece devido à predominância, em território nacional, do sistema de criação animal a pasto, no qual, muitas vezes, o manejo do ecossistema de pastagem não é feito de forma sustentável, afetando negativamente a produtividade animal. Assim, através de estratégias de manejos sustentáveis, é possível maximizar a produção de forragem sem causar prejuízos à perenidade da planta forrageira, beneficiando o desempenho animal (Pimentel et al., 2016; Oliveira et al., 2019).

O manejo sustentável do ecossistema de pastagem é alcançado quando a interação entre os fatores bióticos e abióticos estiverem em equilíbrio, para evitar danos ao sistema produtivo. Adicionalmente, Silva e Nascimento Júnior (2007) descreveram que o manejo da pastagem por meio da sua formação inicial, correção e fertilização do solo, garantindo produtividade forrageira, deve ser considerado incialmente antes da aplicação do manejo do pastejo, definido pelos autores como o gerenciamento de estratégias de pastejo pelos animais do sistema. 
A produtividade de matéria do dossel forrageiro é resultante do acúmulo de forragem das plantas que compõe o sistema de produção, formado por grupamentos de perfilhos em gramíneas, ou ramificações em leguminosas. Neste sentido, o significado de perfilho é definido como a unidade básica de gramíneas forrageiras, e seu desenvolvimento morfológico se baseia em sequências de fitômeros em diferentes estágios de desenvolvimento (Hodgson, 1990). Adicionalmente, o fitômero (Figura 1) é a unidade básica da estrutura de um perfilho, e é formado por lâmina foliar, lígula, bainha foliar, nó, entrenó e gema axilar (Taiz et al., 2017).

Figura 1. Esquematização organizacional de um fitômero em gramínea forrageira. É considerado a unidade básica dos perfilhos, sendo composto por lâmina e bainha foliar, nó, entrenó e gemas axilares. A raiz também pode ser considerada como parte de um fitômero. Nas leguminosas forrageiras, o fitômero é composto por nó, entrenó, estípula, pecíolo e folha. De modo geral, o acúmulo de fitômeros e sua organização espacial resultam no acúmulo de massa do dossel forrageiro, através do desenvolvimento de folhas, colmos e raízes. Isto é resultado do desenvolvimento do perfilho que apresenta interações com seus processos bioquímicos e com fatores externos à planta, resultando no acúmulo de massa seca por perfilho, formando o dossel forrageiro. Por fim, a arquitetura do dossel forrageiro depende da quantidade de fitômeros e perfilhos presentes no sistema, que são influenciados por fatores bióticos e abióticos presentes no ecossistema de pastagem.

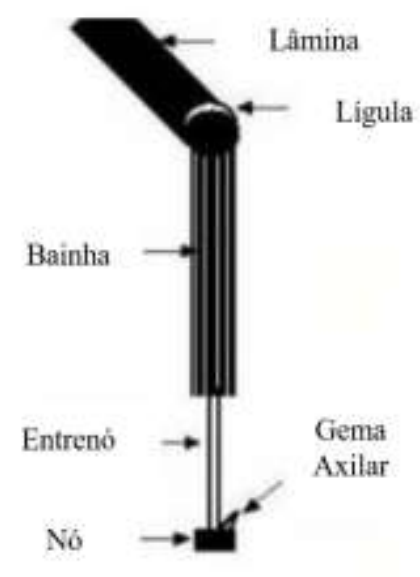

Fonte: Adaptado de Nascimento Júnior e Adese (2004).

Dentro do ecossistema de pastagem, existe um fluxo de massa e energia que mantém o sistema em equilíbrio, através de fatores fisiológicos como regulação hormonal e distribuição de fotoassimilados (Taiz et al., 2017). Ademais, de acordo com Xing et al. (2019), o direcionamento desses fluxos depende de todos os fatores envolvidos no ecossistema de forragem, o qual influenciará na estrutura final do dossel.

As pastagens inseridas no sistema de produção pecuária estão em desfolhações constantes, e a estratégia de manejo do pastejo permite definir a intensidade e frequência que a forragem será pastejada. Neste sentido, visando a recuperação da área foliar pastejada, a planta utiliza todos os recursos disponíveis, principalmente reservas orgânicas, a fim de reestabelecer sua capacidade fotossintética, através do acúmulo de folhas (Xu et al., 2017; Xing et al., 2019). Assim, a perenidade das plantas forrageiras depende de sua capacidade de rebrota após sucessivas desfolhações, mantendo a produtividade do dossel forrageiro (Volenec e Nelson, 2020).

A recuperação da área foliar durante a rebrota de plantas forrageiras obedece a um fluxo de tecidos, no qual, primeiramente, a planta investe seus recursos para a formação de novos tecidos foliares. Logo após a desfolhação, no início da rebrota, a velocidade de crescimento do dossel depende das taxas de alongamento e aparecimento de folhas e perfilhos, resultando no acúmulo de biomassa que será novamente pastejada (Souza et al., 2020). Neste sentido, o aparecimento de 
novas folhas ocorre através da atividade de meristemas apicais e gemas basilares e axilares remanescentes pós-pastejo, e seu crescimento baseia-se no alongamento e aparecimento de folhas para recomposição da área de tecidos fotossinteticamente ativos (Taiz et al., 2017).

Como o crescimento da planta forrageira é dependente das taxas fotossintéticas, a formação de folhas é o principal processo no desenvolvimento vegetal de forragens. Neste sentido, o intervalo entre o aparecimento de duas lâminas foliares é definido como filocrono, que é utilizado para estimar o desenvolvimento de folhas a nível perfilho ou ramificações e pode ser descrita através de dias.folha ${ }^{-1}$ (inverso da taxa de aparecimento de folhas) ou graus-dia.folha ${ }^{-1}$ (Nascimento Júnior e Adese, 2004; Pereira ,2013). Ademais, fatores como época do ano, maturidade da planta, adubação e manejo do pastejo afetam o desenvolvimento da planta forrageira, uma vez que a atividade meristemática para o aparecimento de uma lâmina foliar é regulada, principalmente, pela temperatura e luminosidade (Costa et al., 2015). Adicionalmente, o acúmulo de massa pelo dossel forrageiro é resultado do desenvolvimento individual de perfilhos que resultará na composição morfológica do dossel forrageiro.

Após o reestabelecimento da área foliar, inicia-se o processo de senescência das primeiras folhas expandidas, geralmente localizadas na porção inferior do dossel. Neste sentido, o processo de senescência das folhas se intensifica até que as taxas de aparecimento e senescência se igualem, estabilizando o número de folhas vivas por perfilho (Lemaire e Chapman, 1996). Durante a senescência foliar, a planta forrageira possui capacidade de reciclar nutrientes e utilizar para a formação de novos órgãos vegetativos dando continuidade ao seu processo de crescimento (Bezerra et al., 2020).

Silveira et al. (2010) e Rodrigues et al. (2012) sugeriram a formação de grupos funcionais de plantas forrageiras através de sua avaliação morfogênica, sendo possível descrever como ocorre o desenvolvimento de determinada espécie dentro de um ecossistema. Ademais, ainda segundo os autores, também é possível, com este grupamento, definir quais famílias ou espécies se aproximam morfogeneticamente, ajudando na tomada de decisão dos manejos aplicados a cada tipo de planta forrageira.

Apesar de serem definidas geneticamente, as características morfogênicas de plantas forrageiras são influenciadas pelas condições ambientais do ecossistema de pastagem (Oliveira et al. 2019). Assim, os fluxos energéticos dentro do sistema solo-planta-animal são altamente dependentes da disponibilidade dos recursos naturais.

A estrutura do dossel forrageiro é resultado dos processos morfogênicos, que influenciam na dinâmica do acúmulo de massa seca da planta e seus processos de crescimento e desenvolvimento. De acordo com Sbrissia et al. (2018), a estrutura do dossel forrageiro influencia na produtividade animal, uma vez que afeta seu desempenho de acordo com a qualidade do alimento ofertado durante o pastejo. Desta maneira, com entendimento dos processos morfogênicos da planta forrageira, é possível elaborar planos de gestão da pastagem para que ela possa ser sustentável do ponto de vista ambiental e econômico. Ademais, Morais et al. (2018) descrevem que as avaliações dessas características são diferentes entre gramíneas e leguminosas, devendo ser feita de acordo com a espécie vegetal avaliada. Na Figura 2 é representado um fluxo da produção e utilização de massa seca vegetal, e sua relação com a morfogênese da planta forrageira. 
Figura 2. Esquematização do funcionamento do ecossistema de pastagens. Durante a fase de crescimento, existe a captação de energia luminosa e fixação nos tecidos vegetais, resultando no acúmulo de biomassa vegetal. Neste sentido, o principal processo associado a essa etapa é a fotossíntese, que é controlada pela temperatura, disponibilidade hídrica e nutrientes. Na fase de utilização, ocorre a colheita da planta forrageira através do animal pastejador. Desta forma, a manutenção da estrutura e qualidade do dossel forrageiro é de fundamental importância para que não afete a produtividade animal. Na última fase, a de conversão, existe a transformação da energia contida na forragem consumida em produtos de origem animal. O sucesso dessa fase é diretamente ligado à fase de utilização de forragem. De maneira geral, todas as etapas envolvidas no processo de produção animal em pastagens possuem influência de processos bioquímicos e fisiológicos envolvidos em cada uma delas. Ademais, a estratégia de manejo do pastejo e os fatores de crescimento alteram a morfogênese de plantas forrageiras, refletindo seus efeitos na estrutura final do dossel. Assim, o entendimento da dinâmica do fluxo de energia e massa dentro do ecossistema de pastagem permite a elaboração de estratégias de manejo sustentáveis, maximizando a produção de forragem conciliando com as exigências do animal. Desta maneira, o conhecimento acerca da morfogênese das plantas forrageiras ajuda a entender a dinâmica do crescimento sob diferentes condições de manejo.

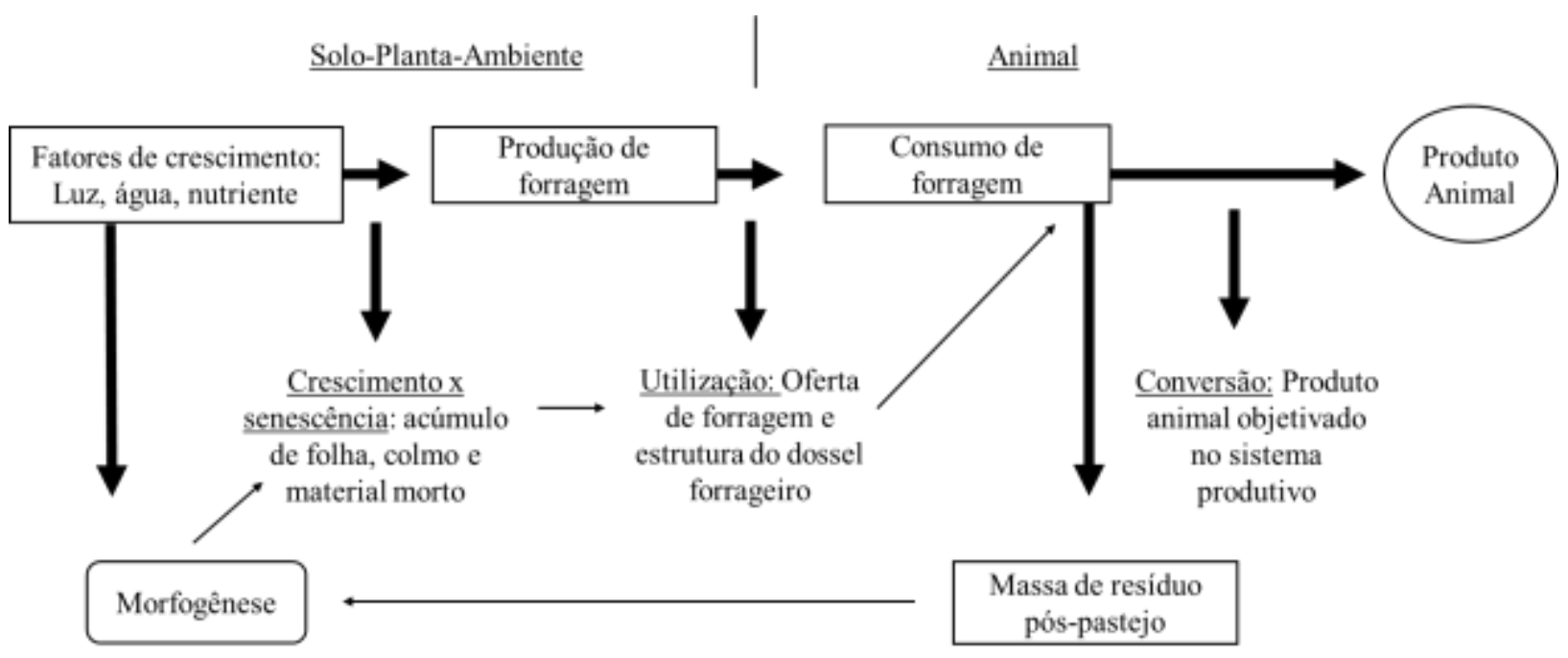

Fonte: Adaptado de Hodgson (1990); Silva e Nascimento Júnior (2007); Santos et al. (2014).

\subsection{Morfogênese e características estruturais em plantas forrageiras}

Os processos de crescimento e desenvolvimento vegetal são controlados por reações fisiológicas que regulam a atividade de produção de biomassa através dos recursos ambientais disponíveis. Neste sentido, o desenvolvimento de sucessivos fitômeros, determinando o aparecimento de novos tecidos vegetais e o acúmulo de massa seca, é resultado do processo de morfogênese (Gastal \& Lemaire, 2015). A morfogênese é definida como a dinâmica de geração e expansão de órgãos vegetais no tempo e espaço que resultam na modificação da arquitetura do dossel forrageiro em resposta a determinado estímulo, seja biótico ou abiótico (Silva e Nascimento Júnior, 2007).

A morfogênese de uma gramínea forrageira em seu estágio vegetativo pode ser descrita através das mensurações da taxa de aparecimento de folhas (TApF), taxa de alongamento de folhas (TAlF), tempo ou duração de vida da folha (DVF) e taxa de alongamento de colmo (TalC) (Pereira, 2013). Em leguminosas, essas medidas são feitas em órgãos diferentes, conforme sua morfofisiologia, e necessitam de maior incentivo experimental para o estudo desse tipo de planta forrageira. Ademais, de acordo com Pereira (2013), a combinação dessas variáveis morfogênicas básicas é responsável pelas principais características estruturais do pasto: comprimento final da folha (CFF), densidade populacional de perfilhos (DPP), número de folhas vivas por perfilho (NFV) e relação lâmina foliar:colmo (RLC), representado na Figura 3. 
Figura 3. Diagrama das relações entre as principais características morfogênicas e estruturais de plantas forrageiras. A TApF possui uma relação direta com a DPP, pois cada folha formada representa a formação de novas gemas axiliares, capazes de gerar um novo perfilho. De maneira geral, altas TApF são relacionadas a maiores densidades de perfilhos pequenos, enquanto uma menor TApF são relacionadas à menor densidade de perfilhos maiores. Assim, a TApF determina as diferenças na estrutura do dossel forrageiro através do seu efeito sobre o tamanho e densidade de perfilhos. A TAlF ocorre em função da divisão e alongamento celular que ocorrem nos meristemas e se correlaciona negativamente com a TApF. O CFF é determinado pela relação entre a TApF e a TAlF, uma vez que o período de crescimento de uma folha é uma fração constante do intervalo de aparecimento de folhas consecutivas. Ademais, enquanto a elevação da TAlF está diretamente correlacionada com maior tamanho final da folha, folhas menores são associadas à maiores TApF. A DVF corresponde ao período de tempo entre o aparecimento de uma folha até sua morte e determina o número máximo de folhas vivas por pefilho. Após atingir seu período máximo de duração, as folhas começam a senescer, dando espaço para o surgimento de outro primórdio foliar. Desta forma, quando um perfilho atinge seu número máximo de folhas vivas, passa a haver um equilíbrio entre o aparecimento e a senescência das folhas, mantendo um número constante de folhas por perfilho. Adicionalmente, a TAlC afeta o aparecimento de folhas e seu comprimento final, em razão do aumento do percurso que a lâmina foliar precisa percorrer para emergir. Além disso, o acúmulo de colmo afeta diretamente a RLC do dossel forrageiro, interferindo nos padrões de pastejo e desempenho animal, por reduzir sua qualidade nutricional.

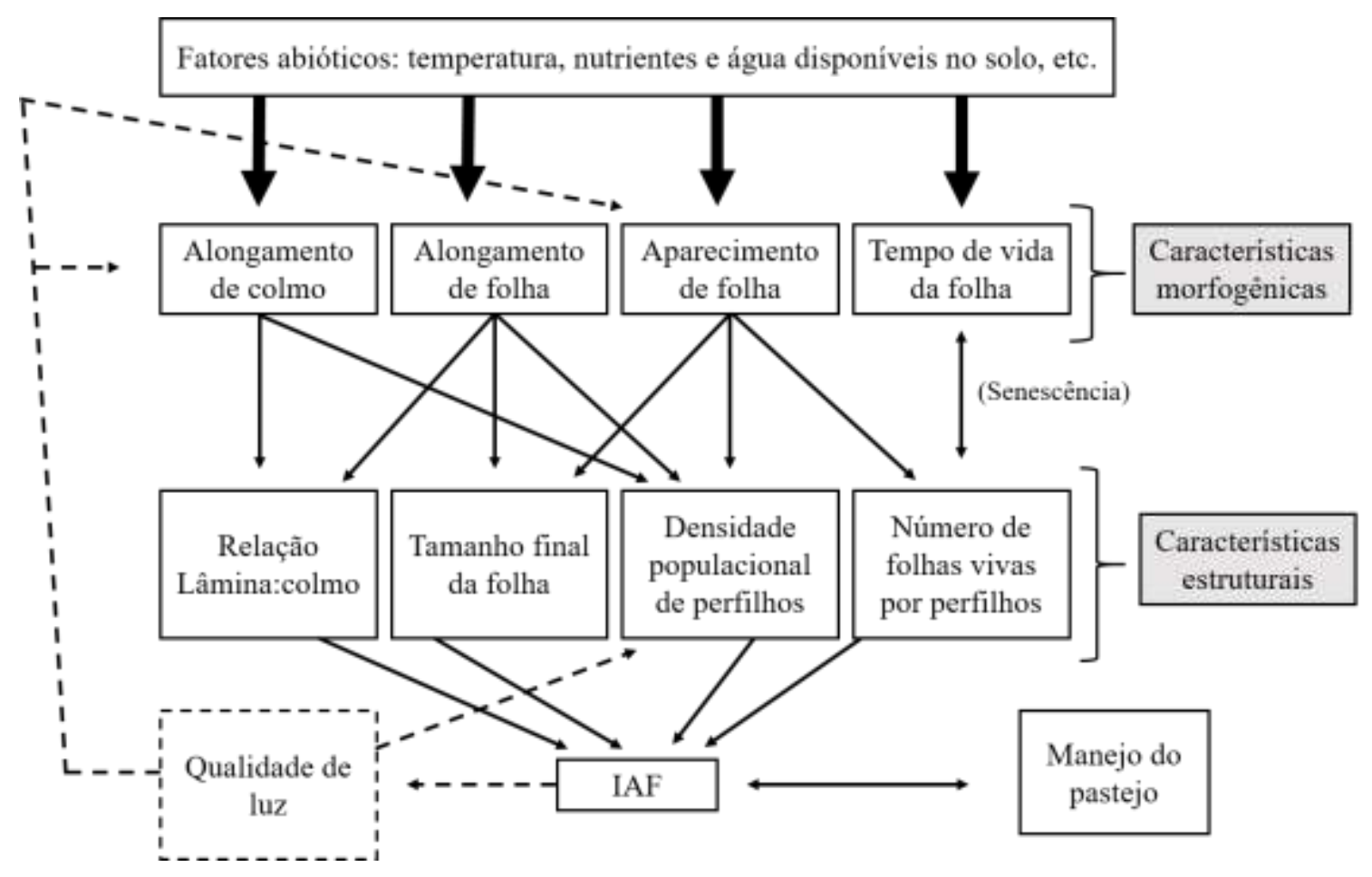

Fonte: Adaptado de Lemaire e Chapman (1996); Silva e Nascimento Júnior (2007); Pereira (2013); Zanine et al. (2019).

De maneira geral, a combinação das variáveis morfogênicas e estruturais do dossel determinam a capacidade de interceptação da radiação solar pelo dossel da pastagem através do seu índice de área foliar (IAF) (Gastal \& Lemaire, 2015). Assim, além de determinar a forma de crescimento de uma planta forrageira, o conhecimento da morfogênese proporciona estimar a qualidade e disponibilidade de forragem e, dessa forma, propor estratégias de manejo direcionada para cada espécie (Braz et al., 2017).

Costa et al. (2018ab) avaliaram as características morfogênicas e estruturais do capim-tanzânia (Megathyrsus maximus [syn. Panicum maximum] cv. Tanzânia) sob diferentes intensidades de desfolha e idades de rebrota, em Boa Vista, Roraima. Desta maneira, através da avaliação das características morfogênicas, os autores concluíram que o manejo desta espécie forrageira dentro deste ecossistema deve ser feito com 35 a $40 \mathrm{~cm}$ de altura pós-desfolha, e não deve ultrapassar 40 dias de período de descanso. Desse modo, a contribuição da avaliação das características morfogênicas e estruturais de uma planta forrageira é um método aliado para definição de estratégias de manejo sustentáveis. 
A formação e arquitetura do dossel forrageiro tem ligação direta com sua densidade populacional de perfilhos, uma vez que o perfilhamento de uma planta é resultante do acúmulo de fitômeros. Segundo Nascimento Júnior e Adese (2004), o potencial de perfilhamento de uma espécie está correlacionado à sua capacidade de emissão de folhas, pois estas correspondem à geração de uma gema axilar capaz de formar um novo perfilho. Ademais, o perfilhamento de uma planta forrageira é um dos mecanismos que garantem a perenidade de plantas forrageiras, visando a substituição contínua de gerações de perfilhos (Jones e Tracy, 2017).

Assim, o acúmulo de biomassa de um dossel forrageiro está diretamente relacionado ao crescimento a nível de perfilhos que resultará em acúmulo de massa seca por área. Adicionalmente, a densidade de perfilhos (DPP) de uma pastagem é resultado do equilíbrio entre as taxas de surgimento e mortalidade dos perfilhos, resultando no balanço entre peso e quantidade de perfilhos (Volenec e Nelson, 2020). Neste sentido, dentro do ecossistema de forragens existe um sistema de compensação entre o tamanho e a densidade populacional de perfilhos. Desta maneira, dosséis mantidos sob maiores alturas possuem menor densidade de perfilhos pesados, enquanto dosséis com alturas menores possuem maior densidade de perfilhos com menor peso (Sbrissia et al. 2018).

Cruz et al. (2019) avaliaram os efeitos de quatro alturas pré-desfolha $(25,35,45$ e $55 \mathrm{~cm})$ nas características estruturais do capim-survenola (Digitaria eriantha cv. Survenola). Os autores relataram maiores acúmulos de massa nas maiores alturas pré-desfolha. No entanto, a partir da análise desses dosséis, foi constatado que houve diminuição da densidade populacional de perfilhos. De maneira geral, a diminuição na população de perfilho em maiores alturas de dosséis é resultado da competição intraespecífica por luz, reduzindo a quantidade de luminosidade no estrato inferior do dossel, causando a “dormência" das gemas que poderiam formar um novo perfilho (Euclides et al., 2019; Yuan et al., 2020). Logo, a estrutura do dossel forrageiro e seu processo de crescimento são afetados pelas interações de fatores de crescimento presentes no sistema solo-planta-animal. Nessa perspectiva, os principais fatores que afetam o desenvolvimento de plantas forrageiras são: temperatura e luminosidade, disponibilidade hídrica e nutrição mineral.

\subsection{Fatores relacionados à morfogênese e estrutura de dosséis forrageiros}

\subsubsection{Temperatura e luminosidade}

De maneira geral, a temperatura e luminosidade controla diversas atividades metabólicas de uma planta, visto que, segundo Taiz et al. (2017), variações nestes fatores ambientais afetam diretamente o desenvolvimento vegetal. A amplitude térmica ambiental do ecossistema de pastagem provoca efeitos na produção de biomassa do dossel forrageiro, causando mudanças na dinâmica do acúmulo de forragem (Andrade et al., 2016).

Neste sentido, Santos et al. (2014) avaliaram o efeito da temperatura do ar diurno/noturno (26/20 ${ }^{\circ} \mathrm{C} ; 29 / 23{ }^{\circ} \mathrm{C} ; 32 / 26$ $\left.{ }^{\circ} \mathrm{C}\right)$ sob características morfogênicas do capim Cenchrus ciliaris cv. Biloela. Os autores relataram que, na maior temperatura, esta espécie respondeu com o aumento das taxas de alongamento, aparecimento e senescência foliar, concomitantemente à redução na duração de vida das folhas (Tabela 1). 
Tabela 1. Variáveis morfogênicas do capim Cenchrus ciliaris cv. Biloela sob três combinações de temperatura diurna/noturna.

\begin{tabular}{|c|c|c|c|c|}
\hline \multirow{2}{*}{ Variáveis Morfogênicas } & \multicolumn{3}{|c|}{ Temperatura do ar (dia/noite) } & \multirow{2}{*}{$\mathrm{CV}^{1} \%$} \\
\hline & $26 / 20^{\circ} \mathrm{C}$ & $29 / 23^{\circ} \mathrm{C}$ & $32 / 26^{\circ} \mathrm{C}$ & \\
\hline Taxa de alongamento foliar $\left(\mathrm{mm} \cdot \mathrm{dia}^{-1}\right)$ & $37,7 \mathrm{c}$ & $45,71 \mathrm{~b}$ & $77,74 \mathrm{a}$ & 9,62 \\
\hline Taxa de aparecimento de folhas (folha.dia ${ }^{-1}$ ) & $0,20 \mathrm{ab}$ & $0,18 \mathrm{~b}$ & $0,21 \mathrm{a}$ & 5,79 \\
\hline Taxa de senescência de foliar $\left(\mathrm{mm} \cdot \mathrm{dia}^{-1}\right)$ & $25,31 \mathrm{~b}$ & $34,12 \mathrm{ab}$ & $41,06 \mathrm{a}$ & 19,53 \\
\hline Duração de vida da folha (dias) & $14,23 \mathrm{~b}$ & $15,38 \mathrm{a}$ & $12,87 \mathrm{c}$ & 5,32 \\
\hline
\end{tabular}

${ }^{1}$ Coeficiente de variação. Médias seguidas por mesmas letras na linha, não diferem entre si pelo teste de Tukey (P>0,05). Fonte: Adaptado de Santos et al. (2014).

Assim, a temperatura ambiental exerce forte controle nas características morfogênicas, alterando as características estruturais do dossel forrageiro, causando modificações nos padrões de acúmulo de forragem que servirá de base para alimentação animal a pasto (Zanini et al., 2012).

Sousa et al. (2011) avaliaram as características morfogênicas do capim-xaraés (Urochloa brizantha cv. Xaraés) desfolhados, quando o dossel atingia 95\% de interceptação luminosa durante o verão e outono de Viçosa, Minas Gerais. Os autores relataram que o outono da região é caracterizado pela redução da temperatura do balanço hídrico no solo. Desta maneira, as plantas de capim-marandu (Urochloa brizantha cv. Marandu) responderam reduzindo suas taxas de alongamento de folhas e no comprimento final da folha, bem como aumentou a duração de vida das folhas, e a taxa de senescência foliar (Tabela 2). Por conseguinte, ainda segundo os autores, o capim-xaraés reduz suas taxas de crescimento durante a época de menor disponibilidade de luz e água, como forma de minimizar os danos causados pela variação climática durante o ano.

Tabela 2. Variáveis morfogênicas de dosséis formados por Urochloa brizantha cv. Xaraés desfolhado com $95 \%$ de interceptação luminosa em duas épocas do ano.

\begin{tabular}{|c|c|c|c|}
\hline \multirow{2}{*}{ Variáveis Morfogênicas } & \multicolumn{2}{|c|}{ Estação do ano } & \multirow{2}{*}{$\mathrm{EPM}^{1}$} \\
\hline & Verão & Outono & \\
\hline Taxa de alongamento foliar (cm.perfilho ${ }^{-1} \cdot$ dia $^{-1}$ ) & $1,54 \mathrm{a}$ & $1,13 \mathrm{~b}$ & 0,034 \\
\hline Taxa de senescência de foliar (cm.perfilho $\left.{ }^{-1} \cdot \mathrm{dia}^{-1}\right)$ & $0,176 \mathrm{~b}$ & $0,358 \mathrm{a}$ & 0,035 \\
\hline Duração de vida da folha (dias) & $70,8 \mathrm{~b}$ & $80,2 \mathrm{a}$ & 2,44 \\
\hline Comprimento final da folha $(\mathrm{cm})$ & $12,2 \mathrm{a}$ & $9,5 \mathrm{~b}$ & 0,25 \\
\hline
\end{tabular}

${ }^{1}$ Erro padrão da média. Médias seguidas por mesma letra na linha não diferem entre si pelo teste $\mathrm{t}$ de Student. (P>0,05). Fonte: Adaptado de Sousa et al. (2011).

O desenvolvimento e crescimento do dossel forrageiro é controlado, principalmente, pela produção de folhas, órgão responsável por absorver a energia solar que chega à parte superior do dossel. Em vista disso, com o aumento do índice de área foliar (IAF), eleva-se a interceptação da radiação fotossinteticamente ativa (RFA) do dossel forrageiro concomitantemente ao acúmulo de massa seca da planta forrageira (Martins et al., 2021).

No entanto, o objetivo de otimizar a produção de forragem de uma área é fornecer uma fonte de alimento para o animal. Desta maneira, é necessário encontrar um equilíbrio entre produção forrageira e produto animal, para que o sistema agropecuário seja sustentável (Silva et al., 2015). Neste sentido, a dinâmica de acúmulo de folhas de um dossel forrageiro se correlaciona com sua interceptação luminosa (IL), em que, quanto maior a altura do dossel, maior a quantidade de luz interceptada (Andrade et al., 2016). Contudo, o padrão de acúmulo de biomassa vegetal de plantas forrageiras é afetado diretamente pela disponibilidade de luz do ambiente. 
Assim, uma planta forrageira acumula principalmente folhas até atingir $95 \%$ de interceptação luminosa, na qual a partir deste ponto, o acúmulo de colmos e material morto se acentua, enquanto a produção de folhas diminui (Pedreira et al., 2017). Portanto, o aumento do IAF resulta em redução e alteração na qualidade da luminosidade que chega ao interior do dossel ocasionando alterações na estrutura do pasto.

Costa et al., (2011) avaliaram o efeito do período de descanso (14, 21, 28, 35 e 42 dias pós-corte) sobre as características morfogênicas de capim-tupi (U. humidicola cv. Tupi) e relataram maiores alturas, seguido de maior acúmulo de massa com o aumento do período de descanso. Entretanto, os autores concluíram que, com o aumento da maturidade da planta, houve redução dos teores de nutrientes como nitrogênio, fósforo, magnésio e potássio, reduzindo, assim, sua qualidade nutricional. Adicionalmente, ainda segundo os resultados encontrados pelos autores, o comprimento final das folhas e sua taxa de senescência foram diretamente proporcionais à idade da planta, enquanto a taxa de aparecimento foliar respondeu de maneira inversa (Tabela 3).

Tabela 3. Variáveis morfogênicas de Urochloa humidicola cv. Tupi em função da idade das plantas.

\begin{tabular}{lccccc}
\hline Variáveis $^{1}$ & \multicolumn{5}{c}{ Idade (dias) } \\
\cline { 2 - 6 } & 14 & 21 & 28 & 35 & 42 \\
\hline TApF & $0,214 \mathrm{a}$ & $0,190 \mathrm{~b}$ & $0,178 \mathrm{c}$ & $0,171 \mathrm{~cd}$ & $0,166 \mathrm{~d}$ \\
CFF & $9,8 \mathrm{c}$ & $11,2 \mathrm{~b}$ & $13,1 \mathrm{a}$ & $13,8 \mathrm{a}$ & $14,0 \mathrm{a}$ \\
TSF & - & - & $0,074 \mathrm{~b}$ & $0,087 \mathrm{a}$ & $0,098 \mathrm{a}$ \\
\hline
\end{tabular}

${ }^{1}$ TApF: Taxa de aparecimento de folhas (folha.dia $\left.{ }^{-1}\right)$; CFF: Comprimento final da folha $(\mathrm{cm})$; TSF: Taxa de senescência foliar $\left(\mathrm{cm}^{-d i a^{-1}}\right)$. Médias seguida de mesma letra na linha não diferem entre si pelo teste de Tukey ( $\mathrm{P}>0,05)$. Adaptado de Costa et al. (2011).

Este padrão de acúmulo com o aumento de período de descanso foi descrito de maneira semelhante para os capins Marandu (Costa et al. 2016a) Xaraés (Costa et al. 2017a) e Mombaça (M. maximus cv. Mombaça) (Costa et al., 2017b). No entanto, o período de descanso necessário para uma planta forrageira depende de sua espécie e do clima da região em que o dossel está sendo manejado, uma vez que a mesma espécie pode se comportar de formas diferentes de acordo com os recursos naturais disponíveis (Pedreira et al., 2017).

A ação climática sobre a dinâmica de crescimento das plantas é um fator que exerce grande influência sobre as características morfofisiológicas do dossel forrageiro. De acordo com Sousa et al. (2011), as variações climáticas alteram a sua arquitetura através das modificações nas características morfogênicas da planta. Neste sentido, Sousa et al. (2019) e Fontes et al. (2020) avaliaram a influência de períodos de insolação (quantidade de luz solar irradiada, em horas) nas características morfogênicas do capim-survenola, e relataram que no período de maior insolação houve maior densidade e taxa de sobrevivência de perfilhos, bem como acúmulo de forragem, resultado da disponibilidade de luz e temperatura para o crescimento da planta, uma vez que não houve limitação hídrica no sistema de avaliação. Ademais, Rizato et al. (2019) corroboram esses resultados ao relatarem que encontraram maior potencial de utilização do capim-survernola nos períodos de maior insolação.

Lopes et al. (2017) avaliaram as características morfogênicas do capim Basilisk (U. decumbens cv. Basilisk) submetido a três graus de sombreamento: controle, moderado e intenso, correspondendo a 0, 20 e $70 \%$ de sombreamento, respectivamente combinado com duas condições de fertilização do solo: com e sem fertilização. Os autores relataram que, com o aumento da intensidade de sombreamento, houve aumento na taxa de alongamento de folhas e colmo (Tabela 4). No entanto, houve redução na densidade populacional de perfilhos com o aumento da intensidade de sombreamento. 
Tabela 4. Variáveis morfogênicas da Urochloa decumbens cv. Basilisk sob diferentes níveis de sombreamento.

\begin{tabular}{|c|c|c|c|c|}
\hline \multirow{2}{*}{ Variáveis ${ }^{1}$} & \multicolumn{3}{|c|}{ Nível de sombreamento (\%) } & \multirow{2}{*}{$\mathrm{EPM}^{2}$} \\
\hline & 0 & 20 & 70 & \\
\hline TAlF (mm.perfilho ${ }^{-1} \cdot$ dia $^{-1)}$ & $15 \mathrm{~b}$ & $18,7 \mathrm{~b}$ & $26 \mathrm{a}$ & 1.45 \\
\hline TAlC (mm.perfilho $\left.{ }^{-1} \cdot \mathrm{dia}^{-1}\right)$ & $3,3 \mathrm{c}$ & $5,1 \mathrm{~b}$ & $6,6 \mathrm{a}$ & 0,59 \\
\hline DPP (perfilho.m ${ }^{-2}$ ) & $928 \mathrm{a}$ & $709 \mathrm{~b}$ & $322 \mathrm{c}$ & 38,3 \\
\hline
\end{tabular}

1TAlF: Taxa de alongamento de folhas; TAlC: Taxa de alongamento de colmo); DPP: Densidade populacional de perfilhos. ${ }^{2}$ Erro padrão da média. Médias seguidas de mesma letra na linha não diferem entre si pelo teste de Tukey ( $\mathrm{P}>0,05)$. Fonte: Adaptado de Lopes et al. (2017).

Assim, Lopes et al. (2017) sugerem que, em solos que não possuem limitação de nutrientes, o sombreamento intenso pode se tornar um fator limitante para o crescimento de plantas forrageiras. No entanto, os autores alertam que, quando existe limitação de nutrientes no solo, o sombreamento moderado ajuda na elevação da DPP, contribuindo para aumentar a persistência do dossel forrageiro.

Nos últimos anos é notável a crescente demanda sobre sistemas de produção integrados na agropecuária. A instalação desses sistemas objetiva diversificar a atividade produtiva de forma sustentável, através de rotação de culturas ou consórcio entre plantas de diferentes espécies, ajudando a preservar o solo, evitando a degradação de pastagens (Bonini et al., 2016). Neste sentido, Neres et al. (2012) avaliaram as características estruturais dos capins Tifton 85 (Cynodon spp.) e Piatã (U. brizantha cv. Piatã) consorciados ou não com feijão-guandu (Cajanus cajan cv. Super N). Os autores relataram, para ambas as gramíneas, redução na altura do dossel, na relação folha:colmo quando consorciadas com o feijão-guandu. Esta redução foi atribuída ao sombreamento exercido pela leguminosa, alterando a quantidade e qualidade da luz que chega ao dossel forrageiro. No entanto, foi relatado que somente o capim Tifton 85 reduziu seu acúmulo de massa seca com o consórcio, levando os autores a concluir que esta espécie não é tolerante ao sombreamento imposto pelo feijão-guandu. Ademais, a não redução no acúmulo de massa seca do capim-piatã se deve à sua plasticidade fenotípica, ou seja, sua capacidade de alterar sua forma de crescimento de acordo com a variação ambiental, sendo uma espécie com potencial para ser utilizada em sistemas integrados. Adicionalmente, o capim-piatã consorciado com sorgo forrageiro não sofreu alterações nas suas características morfogênicas e estruturais, reforçando-se como alternativa para sua utilização em consórcios (Quintino et al., 2016).

Carvalho et al. (2014) avaliaram as características morfogênicas e estruturais do capim-massai (Híbrido de Megathyrsus [syn. Panicum]) em sistemas de cultivo: capim-massai em monocultivo; capim-massai + cajueiros; capim-massai + cajueiros + estilosantes. Os autores não relataram efeito do sombreamento na taxa de senescência e duração de vida das folhas, pois não foi suficiente para acelerar o processo de senescência e morte foliar. No entanto, foi relatado que as maiores taxas de aparecimento de folhas (TApF) e menor filocrono (Tabela 5) foram encontradas quando o capim-massai foi cultivado em monocultivo. Adicionalmente, houve maiores taxas de alongamento de folhas nos dosséis consorciados, como resultado das alterações morfofisiológicas da planta para tentar captar mais luminosidade e manter suas taxas fotossintéticas. Nesse contexto, as alterações resultantes nas plantas estão relacionadas com a capacidade da espécie se adaptar frente a determinador fator, podendo refletir em menor valor nutricional da forragem caso ocorra maiores acúmulos de componentes indesejados como colmo e material morto. 
Tabela 5. Variáveis morfogênicas do capim-massai (Híbrido de Megathyrsus) cultivados em diferentes sistemas.

\begin{tabular}{|c|c|c|c|c|}
\hline \multirow{2}{*}{ Variáveis $^{1}$} & \multicolumn{3}{|c|}{ Sistema de produção ${ }^{2}$} & \multirow{2}{*}{$\mathrm{EPM}^{3}$} \\
\hline & Sistema 1 & Sistema 2 & Sistema 3 & \\
\hline TApF (folhas.dia ${ }^{-1}$ ) & $0,133 \mathrm{a}$ & $0,115 \mathrm{~b}$ & $0,111 \mathrm{~b}$ & 0,002 \\
\hline TAlF (cm.perfilho ${ }^{-1} \cdot \mathrm{dia}^{-1}$ ) & $1,468 \mathrm{~b}$ & $1,913 \mathrm{a}$ & $1,968 \mathrm{a}$ & 0,055 \\
\hline Filocrono (Dias) & $8,0 \mathrm{~b}$ & $9,3 \mathrm{a}$ & $9,9 \mathrm{a}$ & 0,217 \\
\hline
\end{tabular}

1TApF: Taxa de aparecimento de folhas; TAlF: Taxa de alongamento de folha. ${ }^{2}$ Sistema 1: Capim-massai solteiro; Sistema 2: Capim-massai + cajueiros; Sistema 3: Capim-massai + estilosantes + cajueiros. ${ }^{3}$ Erro Padrão da Média Médias seguidas por mesma letra na linha não diferem entre si pelo teste de SNK ( $\mathrm{P}>0,05)$. Fonte: Adaptado de Carvalho et al. (2014).

Desta forma, é evidente que variações na luminosidade exercem influência sobre as características morfogênicas de plantas forrageiras. Este padrão de alongamento de folhas também foi relatado por Paciullo et al. (2011), ao avaliarem espécies de Urochloa em condições de sombreamento.

Ademais, Martuscello et al. (2017) constataram aumento na taxa de alongamento de colmo em dosséis de capimbasilisk como resultado do sombreamento imposto pelo consórcio com milho ou sorgo. No entanto, não foi suficiente para alterar a composição química do dossel forrageiro, sendo registrados valores semelhantes de proteína bruta, fibra em detergente neutro e ácido entre os sistemas de cultivo. Adicionalmente, os autores relatam que consórcio com milho ou sorgo promove aumento no acúmulo de massa seca do capim-basilisk após a retirada das culturas agrícolas. De maneira semelhante, Silva et al. (2020a) relataram os benefícios no acúmulo de massa seca do capim-paiaguás (U. brizantha cv. Paiaguás), após a colheita do sorgo consorciado no sistema integrado.

\subsubsection{Fertilidade do solo}

De maneira geral, a redução da persistência de gramíneas está relacionada, em grande parte, ao manejo inadequado da pastagem, aliado à perda da fertilidade do solo. Neste sentido, a baixa disponibilidade de nutrientes aliada à alta acidez dos solos são fatores que contribuem para limitar a produção de forrageiras. Assim, a calagem é utilizada para elevar o pH do solo através da diminuição da toxicidade do alumínio no solo, favorecendo o desenvolvimento radicular das plantas, permitindo maior persistência no sistema produtivo (Costa et al., 2019ab; 2020ab)

$\mathrm{Na}$ agropecuária, é comum utilizar a adubação focando em atender, principalmente, as exigências da planta em nitrogênio $(\mathrm{N})$, fósforo $(\mathrm{P})$ e potássio $(\mathrm{K})$. Esses elementos são considerados macronutrientes e são divididos em grupos, cuja função na planta é definida por Taiz et al. (2017): Nitrogênio - faz parte de compostos de carbono distribuído por toda planta, além de ser o principal constituinte de clorofilas, proteínas, aminoácidos, enzimas e vários outros compostos essenciais à manutenção da persistência vegetal. É o elemento que as plantas necessitam em maior quantidade e, qualquer deficiência deste elemento inibe rapidamente o crescimento vegetal. Fósforo - composto que participa no armazenamento de energia e integra os açúcares fosfato, que são moléculas ativamente participantes no processo de fotossíntese. Adicionalmente, são utilizados no metabolismo energético das plantas, bem como na composição do DNA e RNA. Potássio - Este elemento permanece na forma iônica, armazenado em vacúolos ou citosol, desempenhando papel crucial na regulação osmótica da folha.

Por atuar diretamente nas taxas de crescimento das plantas forrageiras, o nitrogênio é o elemento que possui a capacidade de estimular o perfilhamento e o fechamento do dossel forrageiro. De acordo com Abreu et al. (2020), a adição de fertilizantes nitrogenados no sistema de pastagem estimula o acúmulo de biomassa da planta forrageira através de respostas morfogênicas. Ademais, o nitrogênio se acumula em zonas de divisão e alongamento foliar, bem como nas zonas meristemáticas auxiliando no processo de formação e crescimento de tecidos vegetais (Taiz et al. 2017). 
Costa et al. (2014) relataram efeito positivo da calagem nas características morfogênicas em dosséis formados por Trachypogon plumosus. Em comparação à testemunha (solo sem correção e adubação), a calagem beneficiou o acúmulo de massa seca, bem como o aparecimento de folhas no dossel forrageiro. Assim, é evidente o papel da correção do solo para a manutenção da produtividade forrageira. Além disso, avaliando a mesma espécie forrageira, Costa et al. (2016bc) relataram o efeito positivo da adubação com fósforo e potássio no acúmulo de forragem e nas características morfogênicas do dossel. O benefício da adubação da utilização de fósforo no sistema produtivo também foi descrito por Costa et al. (2017c) para dosséis formados com capim-mombaça. Ao avaliarem o efeito da fertilização com NPK em dosséis formados por Urochloa decumbens cv. Basilisk, Lopes et al. (2017) relataram que a adubação estimula o aparecimento de folhas, e a elevação da densidade populacional de perfilhos, resultando em maior acúmulo de forragem quando comparado à dosséis que não receberam a fertilização (Tabela 6).

Tabela 6. Taxa de aparecimento de folhas (TApF), densidade populacional de perfilhos (DPP) e acúmulo de forragem de Urochloa brizantha cv. Basilisk na presença e ausência de fertilização com NPK.

\begin{tabular}{cccc}
\hline NPK & $\begin{array}{c}\text { TApF } \\
\left(\text { folha.dia }^{-1}\right)\end{array}$ & $\begin{array}{c}\text { DPP } \\
(\text { perfilho.m }\end{array}$ & $\begin{array}{c}\text { Acúmulo de forragem } \\
\left(\mathrm{kg} . \mathrm{ha}^{-1} \mathrm{de} \mathrm{MS}\right)\end{array}$ \\
\hline Com fertilização & $0,1038 \mathrm{~A}$ & $859 \mathrm{~A}$ & $7402 \mathrm{~A}$ \\
Sem fertilização $_{\text {EPM }^{1}}^{0,0875 \mathrm{~B}}$ & $693 \mathrm{~B}$ & $5206 \mathrm{~B}$ \\
\hline
\end{tabular}

${ }^{1}$ Erro padrão da média. Médias seguidas por letras iguais na coluna não diferem entre si pelo teste de Tukey (P>0,05). Fonte: Adaptado de Lopes et al. (2017).

Avaliando o efeito de doses de nitrogênio (0, 200, 400, 600 e $800 \mathrm{~kg} \cdot \mathrm{ha}^{-1}$ de $\left.\mathrm{N}\right)$ sobre as características do capim-zuri (M. maximus cv. Zuri), Abreu et al. (2020) relataram alterações nas características morfogênicas da planta forrageira. Os autores observaram efeito do nitrogênio nas taxas de alongamento e aparecimento de folhas, bem como para o filocrono e duração de vida das folhas. De maneira geral, o aumento das doses de nitrogênio até $600 \mathrm{~kg}^{-1}$ proporciona elevação nas taxas de aparecimento e alongamento foliar, resultando na diminuição do filocrono, que é fortemente correlacionado de forma negativa com o aparecimento foliar. Ademais, a duração de vida das folhas diminuiu com a adubação nitrogenada por consequência da combinação entre o aparecimento e alongamento foliar. Segundo Gastal \& Lemaire (2015), a menor duração de vida das folhas com o aumento dos níveis de nitrogênio resulta em maior taxa de renovação de tecidos da planta através do aceleramento do fluxo morfogênico durante o crescimento vegetativo.

Martuscello et al. $(2018 ; 2019)$ avaliaram o efeito da adubação com níveis de nitrogênio $(0,50,100,200$ mg.dm-3) sobre as características estruturais dos capins BRS Quenia e BRS Tamani (cultivares híbridas de M. maximus), respectivamente. Em ambas as obras foi relatado aumento na taxa de aparecimento de folhas e redução do filocrono com o aumento das doses de nitrogênio, corroborando a ideia de que essas características se correlacionam de maneira negativa (Tabela 7). 
Tabela 7. Variáveis morfogênicas dos capins BRS Quênia e BRS Tamani (cultivares híbridas de M. maximus) adubados com diferentes doses de nitrogênio.

\begin{tabular}{|c|c|c|c|c|c|c|}
\hline \multirow{3}{*}{ Variável } & \multicolumn{4}{|c|}{ Capim BRS Quênia } & \multirow{3}{*}{ Equação de Regressão } & \multirow{3}{*}{$\mathrm{R}^{2}(\%)^{1}$} \\
\hline & \multicolumn{4}{|c|}{ Dose de N (mg.dm $\left.{ }^{-3}\right)$} & & \\
\hline & 50 & 100 & 150 & 200 & & \\
\hline TApF & 0,13 & 0,15 & 0,17 & 0,19 & $\hat{\mathrm{Y}}=0,11+0,0004 * \mathrm{~N}$ & 76,00 \\
\hline Filocrono & 8,48 & 8,33 & 8,18 & 8,03 & $\hat{\mathrm{Y}}=8,63-0,003 * \mathrm{~N}$ & 82,00 \\
\hline \multirow{3}{*}{ Variável } & \multicolumn{4}{|c|}{ Capim BRS Tamani } & \multirow{3}{*}{ Equação de Regressão } & \multirow{3}{*}{$\mathrm{R}^{2}(\%)^{1}$} \\
\hline & \multicolumn{4}{|c|}{ Dose de $\mathrm{N}\left(\mathrm{mg} \cdot \mathrm{dm}^{-3}\right)$} & & \\
\hline & 50 & 100 & 150 & 200 & & \\
\hline $\mathrm{TApF}$ & 0,089 & 0,099 & 0,108 & 0,118 & $\hat{\mathrm{Y}}=0,08+0,00019^{*} \mathrm{~N}$ & 91,44 \\
\hline Filocrono & 11,09 & 10,14 & 9,18 & 8,23 & $\hat{\mathrm{Y}}=12,05-0,0191 * \mathrm{~N}$ & 88,59 \\
\hline
\end{tabular}

${ }^{1}$ Coeficiente de determinação. Fonte: Adaptado de Martuscello et al. $(2018 ; 2019)$.

Com o aumento do aparecimento de folhas através do estímulo da presença do nitrogênio no solo, o dossel forrageiro tende a aumentar seu índice de área foliar, aumentando também a interceptação luminosa pelo dossel forrageiro (Costa et al., 2015). Ao ampliar sua zona de absorção de energia, ocorre autossombreamento do dossel forrageiro, estimulando o acúmulo de colmo, como uma forma da planta localizar suas folhas jovens nos estratos superiores para obtenção de luz. Neste sentido, com o aumento da disponibilidade de nitrogênio e aumento no aparecimento de folhas, é comum observar elevação na taxa de alongamento de colmos (Abreu et al., 2020). Além disso, como resultado da combinação entre as taxas de crescimento da planta forrageira, a adição de nitrogênio no solo do sistema estimula a elevação na densidade populacional de perfilhos e, consequentemente, o acúmulo de forragem pelo dossel forrageiro (Silva et al. 2015).

Visando diminuir custos com adubação nitrogenada em gramíneas, o consórcio destas espécies com leguminosas está em crescente uso. Lins et al. (2015) avaliaram o capim-tanzânia consorciado com estilosantes Campo Grande (Stylosanthes capitata e $S$. macrocephala) ou adubados com nitrogênio $\left(75,150,225 \mathrm{~kg} \cdot \mathrm{ha}^{-1}\right.$.ano $\left.{ }^{-1} \mathrm{de} \mathrm{N}\right)$. De modo geral, foi observado que não houve diferença nas características morfogênicas do capim-tanzânia entre os dosséis consorciados com leguminosas ou adubados com nitrogênio. Assim, a utilização de leguminosas se mostra promissora para a produção agropecuária nacional. Ratificando esta ideia, Jardim et al. (2020) recomendam o consórcio de capim-xaraés com Estilosantes Campo Grande, pois reduz a necessidade de utilização de adubação com fertilizantes químicos no sistema de produção.

\subsubsection{Disponibilidade hídrica}

A disponibilidade de água no solo é um fator muito importante para a manutenção de plantas forrageiras, uma vez que ela atua em vários mecanismos fisiológicos do vegetal. De maneira geral, a absorção de água pela planta tem por objetivo dissipar a radiação recebida pelas folhas através da transpiração (Taiz et al., 2017). Assim, dosséis forrageiros podem ser beneficiados com o sombreamento, visto que o microclima gerado nos sub-bosques beneficia a retenção de umidade no solo (Quintino et al., 2016).

Neste sentido, de acordo com Duarte et al. (2019), com a redução da disponibilidade de água no solo existe redução na atividade metabólica, afetando a fotossíntese e causando mudanças no crescimento estrutural da planta. Com a escassez hídrica, a absorção de nutrientes é afetada (Taiz et al. 2017), o que, consequentemente, afeta as taxas de crescimento das plantas forrageiras. No entanto, apesar de não ser muito comum, o estresse por alagamento também afeta a morfofisiologia de plantas forrageiras. Em condições de encharcamento, o excesso de água, assim como sua deficiência, pode causar danos na população de plantas, comprometendo sua perenidade (Pimentel et al., 2016). Ademais, segundo Pereira (2013), a taxa de 
senescência de folhas é diretamente afetada por condições de alagamento, por consequência da redução no teor de clorofila e pela reciclagem de nutrientes de folhas senescentes para folhas em processo de expansão.

O entendimento do processo de acúmulo de forragem em condições de variações na disponibilidade hídrica permite a quantificação das respostas em condições adversas. Neste sentido, Kroth et al. (2015) avaliaram o desempenho de três cultivares de $U$. brizantha (cv. Marandu, Piatã e Xaraés) sob três condições de disponibilidade hídrica (solo alagado, capacidade campo e déficit hídrico). Foi observado que, nas situações de estresse por déficit ou excesso de água, as cultivares apresentaram menor acúmulo de massa seca de folhas e colmo. No entanto, a cultivar Marandu apresentou resistência ao alagamento, sendo mais produtiva que as demais cultivares avaliadas (Tabela 8).

Tabela 8. Massa seca de folha e colmo de cultivares de Urochloa brizantha sob diferentes disponibilidades hídricas do solo.

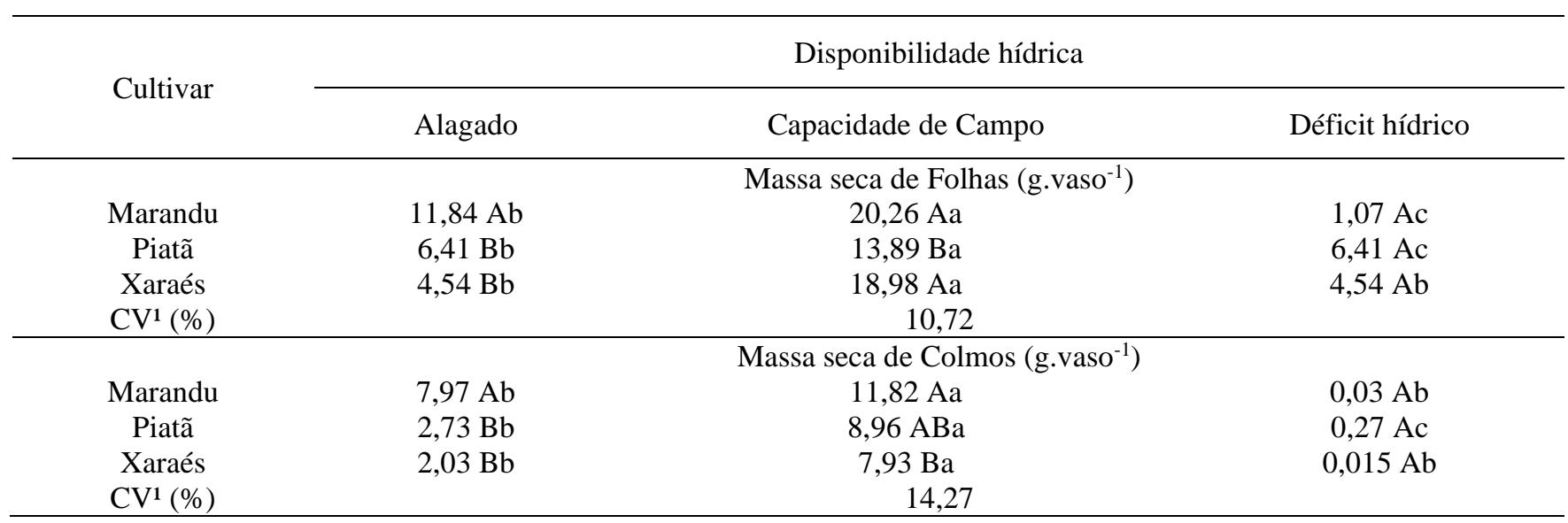

${ }^{1}$ Coeficiente de variação. Médias seguidas por mesma letra maiúscula na coluna e minúscula na linha não diferem entre si pelo Teste de Tukey (P>0,05). Fonte: Adaptado de Kroth et al. (2015).

Duarte et al. (2019) avaliaram a morfogênese de diferentes espécies e cultivares de Urochloa sob estresse hídrico por escassez (50\% e $80 \%$ da capacidade de retenção de umidade do solo) e alagamento (irrigação com 0,1 e 5 cm de lâmina d'água). Nos resultados encontrados pelos autores foi constatado efeito do estresse hídrico nas características morfogênicas das espécies:

- Urochloa humidicola cv. Tully, U. brizantha cv. Xaraés e U. decumbens cv. Basilisk: Não houve efeito de qualquer estresse hídrico sobre as características morfogênicas destas plantas forrageiras, resultado da capacidade de adaptação destas espécies e cultivares ao estresse hídrico, que paralisam seu crescimento como estratégia de sobrevivência.

- U. humidicola cv. Llanero: Houve efeito negativo do alagamento sob a taxa de alongamento de folhas (TAlF) a partir de $1 \mathrm{~cm}$ de lâmina d'agua.

- U. brizantha cv. Piatã: Sob déficit hídrico, esta cultivar aumentou suas taxas de alongamento de folhas e, sob excesso de água, aumentou sua taxa de alongamento de colmo. Desta maneira, o capim-piatã respondeu ao déficit hídrico alongando suas folhas para reduzir os efeitos do estresse.

- U. ruziziensis cv. Kennedy: A deficiência hídrica afetou a taxa de aparecimento de folhas (TApF), filocrono (FIL) e consequentemente na duração de vida das folhas (DVF). Sob escassez de água, o capim Kennedy reduz sua TApF, aumentando o número de dias para o aparecimento de uma nova folha (filocrono), refletindo no aumento da DVF. 
Desta maneira, plantas forrageiras de mesmo gênero podem se responder de formas diferentes ao mesmo estímulo ambiental. Assim, com o conhecimento das características morfogênicas diante aos fatores ambientes, é possível descrever seu padrão de acúmulo e definir qual espécie será utilizada de acordo com sua adaptação ou tolerância ao estresse hídrico.

\subsection{Manejo do pastejo baseado em características morfogênicas e estruturais}

As estratégias de gestão de dosséis forrageiros devem ser definidas visando maximizar a produção de forragem. No entanto, busca-se o equilíbrio entre acúmulo de massa e qualidade nutricional do relvado, visto que a forragem é o principal alimento de animais ruminantes no Brasil. Assim, metas de pastejo estão sendo elaboradas respeitando o sistema solo-plantaanimal, visando encontrar uma forma sustentável de produção de produtos oriundos de animais (Silva et al., 2015).

De acordo com Barbero et al. (2015), em sistemas de produção que utilizam taxas de lotação intermitente, era comum a utilização de períodos de descanso fixos. No entanto, o período de descanso necessário para o dossel forrageiro atingir sua condição de pré-pastejo depende dos fatores ambientais e do manejo do pastejo (Pedreira et al. 2017). Ademais, o resultado do pastejo através do gerenciamento da intensidade e frequência de desfolha causa impactos diretos no dossel forrageiro, determinando sua velocidade de crescimento, produtividade e persistência (Nascimento Júnior e Adese, 2004).

A rebrota do dossel forrageiro pós-desfolha é caracterizada, principalmente, pelo aumento das taxas de aparecimento de folhas, visando recompor sua área fotossinteticamente ativa. No entanto, a partir do momento que o dossel forrageiro alcança 95\% de interceptação de luz, as taxas de acúmulo de colmo e material morto acentuam-se, resultando na modificação estrutural do pasto (Silva et al., 2020b). Adicionalmente, este padrão de acúmulo é bem descrito para espécies de gramíneas temperadas e tropicais, ajudando a definir metas pré-pastejo que maximizem a produção de folhas pelo dossel forrageiro beneficiando a produtividade animal (Barbero et al. 2015)

Neste sentido, através da avaliação morfogênica de plantas forrageiras durante sua rebrota pós-desfolhação, foi possível relacionar o crescimento do dossel forrageiro com suas características estruturais. Desta maneira, o conhecimento sobre as características morfofisiológicas de uma planta forrageira é importante para otimizar os sistemas de produção, respeitando os limites fisiológicos da espécie manejada (Pimentel et al. 2016).

Com o aumento da idade de rebrota, existe redução na qualidade nutricional do dossel forrageiro, decorrente da redução da luminosidade no interior do dossel, que resulta em mudanças estruturais. Como consequência do autossombreamento, a planta forrageira altera sua dinâmica de acúmulo, aumentando sua produção de colmo e de material morto (Costa et al. 2015). Deste modo, maiores intervalos de pastejo geralmente são associados a maiores alturas do dossel forrageiro e, logo, maior acúmulo de massa com composição morfológica indesejada, podendo comprometer o desempenho animal (Souza et al., 2020).

Nessa perspectiva, o acúmulo de colmo contribui para redução da qualidade nutricional da planta forrageira, pois possui menor digestibilidade quando comparado à folha (Silva et al. 2015). Além disso, o colmo constitui uma barreira física para o pastejo do animal, podendo interferir no seu padrão de comportamento ingestivo, afetando seu desempenho individual e, consequentemente, a produtividade da pecuária (Delevatti et al., 2019; Oliveira et al. 2019). Desta maneira, a elaboração de metas de pastejo objetivando controlar o acúmulo de materiais indesejados no dossel forrageiro foram descritas com o auxílio da descrição morfogênica das plantas.

Sales et al. (2014) avaliaram o padrão de rebrota do capim Pioneiro (Pennisetum purpureum cv. Pioneiro) submetido a estratégias de desfolhação pré-pastejo (95 e 100\% de IL pelo dossel), e relataram redução na taxa de aparecimento foliar quando o pasto foi manejado com maiores alturas (100\% de IL). Assim, ao afetar o fluxo de geração de tecidos (morfogênese), o resultado final é refletido na estrutura final do dossel forrageiro, visto que Pereira et al. (2013) relataram redução na 
densidade populacional de perfilhos do capim Napier ( $P$. purpureum cv. Napier) quando a estratégia de manejo foi correspondente a $100 \%$ de IL. No entanto, apesar de reduzir a quantidade de perfilhos, quando o dossel forrageiro passa a interceptar luminosidade acima de 95\%, existe maior acúmulo de colmo e de material morto, provenientes do aumento da taxa de alongamento desse órgão e da taxa de senescência foliar, afetando negativamente a composição química da pastagem (Oliveira et al. 2019).

Zanini et al. (2012) avaliaram o capim-aruana (M. maximus cv. Aruana) sob duas condições do dossel forrageiro prépastejo: entrada dos animais quando o dossel atingia 95 e $98 \%$ de interceptação luminosa. Segundo resultados encontrados pelos autores, os dosséis manejados com $98 \%$ de IL no pré-pastejo obtiveram maiores taxas de alongamento de colmo e senescência de folhas, bem menor densidade populacional de perfilhos (DPP) e número de folhas vivas por perfilho (Tabela 9).

Tabela 9. Variáveis morfogênicas de dosséis forrageiros formados por Megathyrsus maximus cv. Aruana em duas condições pré-pastejo com base na interceptação luminosa.

\begin{tabular}{|c|c|c|c|}
\hline \multirow{2}{*}{ Variável Morfogênica } & \multicolumn{2}{|c|}{ Interceptação de luz pelo dossel } & \multirow{2}{*}{$\mathrm{EPM}^{1}$} \\
\hline & $95 \%$ & $98 \%$ & \\
\hline Taxa de senescência foliar (cm.perfilho ${ }^{-1} \cdot$ dia $\left.^{-1}\right)$ & $0,184 \mathrm{~b}$ & $0,291 \mathrm{a}$ & 0,020 \\
\hline Taxa de alongamento de colmo (cm.perfilho $\left.{ }^{-1} \cdot \mathrm{dia}^{-1}\right)$ & $0,099 \mathrm{~b}$ & $0,205 \mathrm{a}$ & 0,013 \\
\hline Densidade populacional de perfilhos (perfilhos. $\mathrm{m}^{-2}$ ) & $1.424 \mathrm{a}$ & $1.048 \mathrm{~b}$ & 48,00 \\
\hline Número de folhas vivas por perfilho & $3,7 \mathrm{a}$ & $3,4 \mathrm{~b}$ & 0,030 \\
\hline
\end{tabular}

Médias seguidas por mesma letra na linha não diferem entre si pelo teste $t$ de Student. ( $\mathrm{P}>0,05)$. Adaptado de Zanini et al. (2012).

Nesta perspectiva, dosséis manejados com interceptação de luz acima dos 95\% geralmente acumulam maior massa de forragem, com maior proporção de colmo e material morto como consequência da competição por luz dentro do dossel forrageiro (Silva et al. 2015). De maneira geral, os padrões de fluxo de tecidos em plantas forrageiras tropicais e temperadas são bem descritos, mostrando que a arquitetura do dossel forrageiro e sua captação de luz estão diretamente relacionadas às suas características morfogênicas e estruturais (Gastal \& Lemaire, 2015). Deste modo, o conhecimento das respostas morfogênicas auxilia na elaboração de metas de desfolhação que beneficie a produção de forragem de qualidade. Assim, de fato, são reconhecidos os padrões de acúmulos dos componentes morfológicos de gramíneas forrageiras de acordo com o nível de interceptação de luz. No entanto, as frequências e intensidades de pastejo têm capacidade de alterar a dinâmica de crescimento do dossel forrageiro através da remoção de órgãos (folha e colmo), modificando a captura de luz da planta.

Silva Neto et al. (2019) avaliaram as características do capim-marandu sob diferentes estratégias de pastejo, considerando diferentes alturas $(\mathrm{cm})$ de pré e pós-pastejo, respectivamente: 25/10; 25/15; 35/15; 45/15. Os autores relataram menores taxas de aparecimento de folhas para estratégia de manejo desfolhado com maior frequência $(25 / 10 \mathrm{~cm})$, sendo explicado pelo fato da remoção de folhas em períodos curtos de tempo entre os períodos de pastejo (Tabela 10). Desta maneira, as plantas de capim-marandu, nesta estratégia de pastejo, não tiveram tempo suficiente para o aparecimento de novas folhas. Ademais, foi relatado pelos autores, aumento no filocrono das plantas manejadas com 25/10 cm (Tabela 10), sendo ratificado a correlação negativa entre esta variável e a TApF. Apesar de registrarem maiores taxas de alongamento de colmo nesta estratégia, os autores descrevem que não foi suficiente para alterar a estrutura do dossel forrageiro. 
Tabela 10. Variáveis morfogênicas de Urochloa brizantha cv. Marandu sob diferentes estratégias de pastejo.

\begin{tabular}{|c|c|c|c|c|c|}
\hline \multirow{2}{*}{ Variável morfogênica ${ }^{1}$} & \multicolumn{4}{|c|}{ Estratégia de pastejo $(\mathrm{cm})$} & \multirow[t]{2}{*}{$\mathrm{EPM}^{2}$} \\
\hline & $25 / 10$ & $25 / 15$ & $35 / 15$ & $45 / 15$ & \\
\hline TApF (folhas.perfilho ${ }^{-1} \cdot$ dia $^{-1}$ ) & $0,048 \mathrm{a}$ & $0,041 \mathrm{~b}$ & $0,047 \mathrm{a}$ & $0,049 \mathrm{a}$ & 0,002 \\
\hline Filocrono (dias) & $24,72 \mathrm{~b}$ & $30,53 \mathrm{a}$ & $25,08 \mathrm{~b}$ & $23,36 \mathrm{~b}$ & 0,910 \\
\hline TAlC (mm.dia $\left.{ }^{-1}\right)$ & $0,27 \mathrm{~b}$ & $0,65 \mathrm{a}$ & $0,46 \mathrm{~b}$ & $0,39 \mathrm{~b}$ & 0,110 \\
\hline
\end{tabular}

${ }^{1}$ TApF: Taxa de aparecimento de folhas; TAlC: Taxa de alongamento de colmo. Médias seguidas por mesma letra na linha não diferem entre si pelo teste de Tukey (P>0,05). Fonte: Adaptado de Silva Neto et al. (2019).

Em lotação contínua, Migliorini et al. (2018) avaliaram quatro alturas de pastejo (10, 20, 30 e $40 \mathrm{~cm})$ em dosséis formados por capim-papuã ( $U$. plantaginea) e relataram que, nos dosséis manejado com maior altura, houve redução na taxa de aparecimento foliar, o que resultou numa menor densidade populacional de perfilhos. Adicionalmente, nos dosséis manejados com $40 \mathrm{~cm}$ de altura, observou-se maior acúmulo de forragem proveniente dos acúmulos de colmo e material morto. Nesta situação, maiores alturas de pastejo contínuo podem apresentar uma estrutura desfavorável ao animal e comprometer seu desempenho, afetando negativamente a produtividade pecuária. Desta maneira, o conhecimento acerca das características morfofisiológicas e seus mecanismos de tolerância aos estresses são de fundamental importância para o manejo das pastagens.

\section{Considerações Finais}

Os componentes bióticos e abióticos existentes no ecossistema de plantas forrageiras atuam como fatores que exercem grande influência sobre as características de uma planta. O crescimento vegetal é baseado em um fluxo de tecidos, através de alongamento e divisão celular, formando cada órgão morfológico da planta forrageira.

O ambiente de pastagem é suscetível a diversas variações ambientais que refletem na produtividade vegetal. No entanto, a inclusão do animal no sistema é um fator importante, visto que, através do pastejo, é possível alterar as características do dossel forrageiro. Assim, através da avaliação morfogênica de uma planta, é possível conhecer seu padrão de crescimento e correlacionar as relações entre ambiente e resposta vegetal, auxiliando no processo de tomada de decisões sobre o manejo de pastagens.

A alta atividade agropecuária em áreas de pastagens no Brasil demanda uma necessidade de buscar formas de manejo que mantenham o equilíbrio entre produção de forragem e ingestão e desempenho animal. Neste sentido, a avaliação das características morfogênicas de gramíneas frente a novas estratégias de gerenciamento de pastagens possibilita a compreensão do desenvolvimento de dosséis forrageiros, visto que dentro do ambiente pastoril, ocorre alterações fisiológicas para sobrevivência e persistência da planta forrageira. Desta maneira é possível entender os limites morfofisiológicos de uma gramínea e elaborar metas de pastejo que maximize a produção de forragem com maior qualidade.

De maneira geral, a utilização dos conhecimentos acerca dos padrões de crescimento de plantas forrageiras a determinado estímulo tem gerado conhecimentos necessários ao manejo das pastagens tropicais. Adicionalmente, a avaliação destas características frente a diversos fatores estressantes em um ecossistema de pastagem é necessária à compreensão dos mecanismos vegetais envolvidos em cada espécie de planta.

\section{Referências}

Abreu, M. J. I., Paula, P. R. P., Tavares, V. B., Cidrini, I. A., Nunes, H. O., Emiliano, W. J. C., Coelho, R. M., Neiva Júnior, A. P., \& Tomaz, C. E. P. (2020). Morfogênese, características estruturais e acúmulo de forragem do Megathyrsus maximus BRS Zuri submetido a adubação nitrogenada. Boletim De Indústria Animal, 77(1), 1-17. DOI: https://doi.org/10.17523/bia.2020.v77.e1486 
Andrade, A. S., Santos, P. M., Pezzopane, J. R. M., Araújo, L. C., Pedreira, B. C., Pedreira, C. G. S., Marin, F. R., \& Lara, M. A. S. (2016). Simulating tropical forage growth and biomass accumulation: an overview of model development and application. Grass and Forage Science, 71(1), 54-65. DOI: https://doi.org/10.1111/gfs.12177

Barbero, L. M., Basso, K. C., Igarasi, M. S., Paiva, A. J., \& Basso, F. C. (2015). Respostas morfogênicas e estruturais de plantas tropicais submetidas à desfolhação. Boletim de Indústria Animal, 72(4), 321-330. DOI: https://doi.org/10.17523/bia.v72n4p321

Bezerra, J. D. V., Emereciano Neto, J. V., Alves, D. J. S., Batista Neta, I. E., Galdino Neto, L. C., Santos, R. S., \& Difante, G. S. (2020). Características produtivas, morfogênicas e estruturais de cultivares de Brachiaria brizantha cultivadas em dois tipos de solo. Research, Society and Development, 9(7), e129972947. DOI: https://doi.org/10.33448/rsd-v9i7.2947

Bonini, C. S. B., Lupatini, G. C., Andrighetto, C., Mateus, G. P., Heinrichs, R., Aranha, A. S., Santana, E. A. R., \& Meirelles, G. C. (2016) Produção de forragem e atributos químicos e físicos do solo em sistemas integrados de produção agropecuária. Pesquisa Agropecuária Brasileira, 51(9), 1695-1698. DOI: https://doi.org/10.1590/s0100-204x2016000900070

Braz, T. G. S., Martuscello, J. A., Santos, M. E. R., \& Pereira, V. V. (2017). Análise de correlação parcial no estudo da morfogênese e do acúmulo de forragem de Panicum maximum cv.'Tanzânia'. Ciência Rural, 47(9), e20161058. DOI: https://doi.org/10.1590/0103-8478cr20161058

Carvalho, W. F., Moura, R. L., Santos, M. S., Silva, S. F., \& Leal, T. M. (2014). Morfogênese e estrutura de capim-massai em diferentes sistemas de cultivo sob pastejo. Revista Brasileira de Agropecuária Sustentável, 4(1), 28-37. DOI: https://doi.org/10.21206/rbas.v4i1.233

Costa, N. L., Paulino, V. T., Moraes, A., \& Magalhaes, J. A. (2011) Produção de forragem, composição química e morfogênese de Brachiaria humidicola cv. Tupi em diferentes idades de corte. PUBVET, 5(8), 1044.

Costa, N. L., Moraes, A. D., Carvalho, P. C. F., Monteiro, A. L. G., Motta, A. C. V., Silva, A. L. P., \& Oliveira, R. A. (2014). Morfogênese de Trachypogon plumosus sob calagem, adubação e idades de rebrota. Archivos de Zootecnia, 63(241), 109-120.

Costa, N. L.; Paulino, V. T.; Magalhães, J. A.; Rodrigues, B. H. N. \& Rodrigues, A. N. A. (2015). Produção de forragem, composição química e morfogênese de Cynodon dactylon cv. Vaquero sob níveis de nitrogênio. PUBVET, 9(6), 258-261.

Costa, N. L.; Townsend, C. R.; Fogaça, F. H. S.; Magalhães, J. A.; Santos, F. J. S. \& Rodrigues, B. H. N. (2016a). Rendimento de forragem e morfogênese de Brachiaria brizantha cv. Marandu sob diferentes períodos de descanso. PUBVET, 10(4), 271-355.

Costa, N. L., Moraes, A., Carvalho, P. C. F., \& Magalhães, J. A. (2016b) Acúmulo de forragem e morfogênese de Trachypogon plumosus sob níveis de fósforo. PUBVET, 10(5), 388-393.

Costa, N. L., Moraes, A., Carvalho, P. C. F., \& Magalhães, J. A. (2016c). Rendimento de forragem e morfogênese de Trachypogon plumosus sob níveis de potássio. PUBVET, 10(5), 394-398.

Costa, N. L., Townsend, C. R., Magalhães, J. A., Fogaça, F. H. S., \& Santos, F. J. S. (2017a). Dinâmica do acúmulo de forragem e morfogênese de Urochloa brizantha cv. Xaraés sob períodos de descanso. PUBVET, 11(5), 424-537.

Costa, N. L., Jank, L., Magalhães, J. A., Rodrigues, A., Fogaça, F. H. S., Bendahan, A. B., \& Santos, F. J. S. (2017b). Produtividade de forragem, composição química e morfogênese de Megathyrsus maximus cv. Mombaça sob períodos de descanso. PUBVET, 11(11), 1169-1174.

Costa, N. L., Jank, L., Magalhães, J. A., Fogaça, F. H. S., Rodrigues, A. N. A., \& Santos, F. J. S. (2017c). Acúmulo de forragem e morfogênese de Megathyrsus maximus cv. Mombaça sob níveis de fósforo. PUBVET, 11(11), 1163-1168.

Costa, N. D. L., Jank, L., Magalhães, J. A., Rodrigues, A. N. A., Fogaça, F. H. S., Bendahan, A. B., \& Santos, F. D. S. (2018a). Características morfogênicas e estruturais de Megathyrsus maximus cv. Tanzânia-1 sob intensidades de desfolhação. PUBVET, 12(4), 1-7. DOI: https://doi.org/10.22256/pubvet.v12n4a67.17

Costa, N. L., Jank, L., Fogaça, F. H. S., Magalhães, J. A., Bendahan, A. B., Santos, F. J. S., \& Rodrigues, B. H. N. (2018b). Rendimento de forragem, composição química e morfogênese de Megathyrsus maximus cv. Tanzânia-1 sob frequências de desfolhação. PUBVET, 12(4), 1-7. DOI: https://doi.org/10.22256/pubvet.v12n4a68.1-7

Costa, N. L., Moraes, A., Carvalho, P. C. F., Magalhães, J. A., Rodrigues, B. H. N., \& Santos, F. J. S. (2019a). Acúmulo de forragem e morfogênese de Axoponus aureus sob adubação potássica. Research, Society and Development, 8(8), e49881270. DOI: http://dx.doi.org/10.33448/rsd-v8i8.1270

Costa, N. L., Rodrigues, A. N. A., Magalhães, J. A., Bendahan, A. B., Rodrigues, B. H. N., \& Santos, F. J. S. (2019b). Morfogênese e composição química de Brachiaria humidicola cv. Llanero sob períodos de descanso. Research, Society and Development, 8(10), e228101356. DOI: http://dx.doi.org/10.33448/rsdv8i10.1356

Costa, N. L., Magalhães, J. A., Bendahan, A. B., Rodrigues, A. N. A., Rodrigues, B. H. N., \& Santos, F. J. S. (2020a). Produtividade de forragem e morfogênese de Brachiaria ruziziensis sob níveis de nitrogênio. Research, Society and Development, 9(1), e10911499. DOI: http://dx.doi.org/10.33448/rsdv9i1.1499

Costa, N. L., Rodrigues, A. N. A., Magalhães, J. A., Bendahan, A. B., Rodrigues, B. H. N., \& Santos, F. J. S. (2020b). Rendimento de forragem, composição química e morfogênese de Brachiaria brizantha cv. Piatã sob períodos de rebrota. Research, Society and Development, 9(1), e133911801. DOI: http://dx.doi.org/10.33448/rsd-v9i1.1801

Cruz, N. T., Sousa, B. M. L., Fagundes, J. L., Backes, A. A., Gusmão Filho, J. D., Vilas-Bôas, R. T., Rizato, C. A., \& Barbosa, L. T. (2019). Herbage accumulation dynamics in digit grass subjected to defoliation frequencies. Semina: Ciências Agrárias, 40(2), 731-744. DOI: https://doi.org/10.5433/16790359.2019v40n2p731

Delevatti, L. M., Cardoso, A. S., Barbero, R. P., Leite, R. G., Romanzini, E. P., Ruggieri, A. C., \& Reis, R. A. (2019). Effect of nitrogen application rate on yield, forage quality, and animal performance in a tropical pasture. Scientific Reports, 9(1), 1-9. DOI: https://doi.org/10.1038/s41598-019-44138-X 
Duarte, C. F. D., Prochera, D. L., Paiva, L. M., Fernandes, H. J., Biserra, T. T., Cassaro, L. H., Flores, L. S., \& Fernandes, R. L. (2019). Morfogênese de braquiárias sob estresse hídrico. Arquivo Brasileiro de Medicina Veterinária e Zootecnia, 71(5), 1669-1676. DOI: https://doi.org/10.1590/1678-4162-10844

Euclides, V. P. B., Montagner, D. B., Macedo, M. C. M., Araújo, A. R., Difante, G. S., \& Barbosa, R. A. (2019). Grazing intensity affects forage accumulation and persistence of Marandu palisadegrass in the Brazilian savannah. Grass and Forage Science, 74(3), 450-462. DOI: https://doi.org/10.1111/gfs.12422

Fontes, P. T. N., Sousa, B. M. L., Oliveira Júnior, L. F. G., Fagundes, J. L., Backes, A. A., Nascimento, G. A., Florêncio, R. S. R., \& Santos, A. L. H. (2020). Population dynamics and structural characteristics of' Survenola digit grass subjected to intermittent defoliation strategies. Pesquisa Agropecuária Brasileira, 55(Epub), e01602. DOI: https://doi.org/10.1590/s1678-3921.pab2020.v55.01602

Gastal, F., \& Lemaire, G. (2015). Defoliation, shoot plasticity, sward structure and herbage utilization in pasture: Review of the underlying ecophysiological processes. Agriculture, 5(4), 1146-1171. DOI: https://doi.org/10.3390/agriculture5041146

Hodgson, J. (1990). Grazing management-science into practice. Essex: Longman Scientific \& Technical, 203p.

Jardim, R. R., Fries, D. D., Dias, D. L. S., Figueiredo, A. J., Pires, A. J. V., Teixeira, F. A., Amaral Júnior, F. P., \& Paiva, L. S. (2020). Effect of intercropping and nitrogen fertilization on production characteristics of Stylosanthes cv. Campo Grande and Xaraés grass. Grassland Science, 67(1), 48-54. DOI: https://doi.org/10.1111/grs.12286

Jones, G. B., \& Tracy, B. F. (2017). Persistence and productivity of orchardgrass and orchardgrass/alfalfa mixtures as affected by cutting height. Grass and Forage Science, 73(2), 544-552. DOI: https://doi.org/10.1111/gfs.12309

Kroth, B. E., Bonfim-Silva, E. M., Silva, T. J., Koetz, M., \& Schlichting, A. F. (2015). Cultivares de Brachiaria brizantha sob diferentes disponibilidades hídricas em Neossolo Flúvico. Revista Brasileira de Engenharia Agrícola e Ambiental - Agriambi, 19(5), 464-469. DOI: http://dx.doi.org/10.1590/18071929/agriambi.v19n5p464-469

Lemaire, G., \& Chapman, D. (1996). Tissue fluxes in grazing plant communities. In: Hodgson, J. \& Illius, A. W. (Eds.). The ecolog y and management of grazing systems. Wallingford: CAB International, p.3-36.

Lins, T. O. J. D., Cecato, U., Pinheiro, A. A., Iwamoto, B. S., Krutzmann, A., Beloni, T., \& Silva, R. R. (2015). Características morfogênicas do capimTanzânia consorciado com Estilosantes Campo Grande ou adubado com nitrogênio sob pastejo. Semina: Ciências Agrárias, 36(4), 2739-2752. DOI: https://doi.org/10.5433/1679-0359.2015v36n4p2739

Lopes, C. M., Paciullo, D. S. C., Araújo, S. A. C., Morenz, M. J. F., Gomide, C. A. M., Maurício, R. M., \& Braz, T. G. S. (2017). Plant morphology and herbage accumulation of signal grass with or without fertilization, under different light regimes. Ciência Rural, 47(2), e20160472. DOI: https://doi.org/10.1590/0103-8478cr20160472

Martins, C. D. M., Schmitt, D., Duchini, P. G., Miqueloto, T., \& Sbrissia, A. F. (2021). Defoliation intensity and leaf area index recovery in defoliated swards: implications for forage accumulation. Scientia Agricola, 78(2), e20190095. DOI: https://doi.org/10.1590/1678-992x-2019-0095

Martuscello, J. A., Amorim, P. L., Ferreira, P. S., Ribeiro, L. S., \& Souza, M. W. (2017). Morfogênese e estrutura do capim-braquiária em sistema de integração agricultura e pecuária. Revista Ciência Agrícola, 15(1), 33-42.

Martuscello, J. A., Ribeiro, Y. N., Braz, T. G. S., Ferreira, M. R., Assis, J. A., Jank, L., \& Reis, G. A. (2018). Produção de forragem, morfogênese e eficiência agronômica do adubo em Capim BRS Quênia sob doses de nitrogênio. Boletim de Indústria Animal, 75, 1-12. DOI: https://doi.org/10.17523/bia.2018.v75.e1411

Martuscello, J. A., Rios, J. F., Ferreira, M. R., Assis, J. A., Braz, T. G. S., \& Cunha, D. V. (2019). Produção e morfogênese de capim BRS Tamani sob diferentes doses de nitrogênio e intensidades de desfolhação. Boletim de Indústria Animal, 76, 1-10. DOI: https://doi.org/10.17523/bia.2019.v76.e1441.

Migliorini, F., Soares, A. B., Schmitt, D., Pontes, L. S., \& Assmann, T. S. (2018). Morphogenetic and structural characteristics of alexandergrass pastures under continuous stocking. Ciência Animal Brasileira, 19(e-50830), 1-11. DOI: https://doi.org/10.1590/1809-6891v19e-50830

Morais, L. F., Carvalho, C. A. B., Anjos, A. N. A., Viegas, C. R., \& Silva, P. H. F. (2018). Avanços na avaliação de pastagens cultivadas com forrageiras tropicais no Brasil: Uma Revisão. Brazilian Journal of Applied Technology for Agricultural Science, 11(2), $125-136$.

Nascimento Júnior, D., \& Adese, B. (2004). Acúmulo de biomassa na pastagem. In: Simpósio Sobre Manejo Estratégico de Pastagem, 2., Viçosa. Anais.. Viçosa: UFV, 2004. p. 289-346.

Neres, M. A., Castagnara, D. D., Silva, F. B., Oliveira, P. S. R., Mesquita, E. E., Bernardi, T. C., Guarianti, A. J., \& Vogt, A. S. L. (2012). Características produtivas, estruturais e bromatológicas dos capins Tifton 85 e Piatã e do feijão-guandu cv. Super N, em cultivo singular ou em associação. Ciência Rural, 42(5), 862-869. DOI: https://doi.org/10.1590/S0103-84782012000500017

Oliveira, R. T., Barbosa, R. A., Oliveira, C. V. V., Paludo, F., \& Fernandes, P. B. (2019). Multivariate of forage biomass, nutritional value and animal performance in pastures of Brachiaria brizantha. Colloquium Agrariae, 15(4), 107-113.

Paciullo, D. S. C., Fernandes, P. B., Gomide, C. A. M., Castro, C. R. T., Sobrinho, F. S., \& Carvalho, C. A. B. (2011). The growth dynamics in Brachiaria species according to nitrogen dose and shade. Revista Brasileira de Zootecnia, 40(2), 270-276. DOI: https://doi.org/10.1590/S1516-35982011000200006

Pedreira, C. G., Braga, G. J., \& Portela, J. N. (2017). Herbage accumulation, plant-part composition and nutritive value on grazed signal grass (Brachiaria decumbens) pastures in response to stubble height and rest period based on canopy light interception. Crop and Pasture Science, 68(1), 62-73, DOI: https://doi.org/10.1071/CP16333

Pereira, L. E. T., Paiva, A. J., Geremia, E. V., \& Silva, S. C. (2013). Regrowth patterns of elephant grass (Pennisetum purpureum Schum.) subjected to strategies of intermittent stocking management. Grass and Forage Science, 70(1), 195-204. DOI: https://doi.org/10.1111/gfs.12103 
Pereira, V. V. (2013). A Importância das Características Morfogênicas sobre o Fluxo de Tecidos no Manejo de Pastagens Tropicais. Revista em Agronegócio e Meio Ambiente, 6(2), 289-309. DOI: https://doi.org/10.17765/2176-9168.2013v6n2p\%25p

Pereira, A. S., Shitsuka, D. M., Parreira, F. J., \& Shitsuka, R. (2018). Metodologia da pesquisa científica. [e-book]. Santa Maria. Ed. UAB/NTE/UFSM. Recuperado de: https://repositorio.ufsm.br/bitstream/handle/1/15824/Lic_Computacao_Metodologia-Pesquisa-Cientifica.pdf?sequence=1.

Pimentel, R. M., Bayão, G. F V., Lelis, D. L., Cardoso, A. J. S., Saldarriaga, F. V., Melo, C. C. V., Souza, F. B. M., Pimentel, A. C. S., Fonseca, D. M., \& Santos, M. E. R. (2016). Ecophysiology of forage plants. PUBVET, 10(9), 666-679.

Quintino, A. D. C., Almeida, R. G., Abreu, J. G., \& Macedo, M. C. M. (2016). Características morfogênicas e estruturais do capim-piatã em sistema de integração lavoura-pecuária. Veterinária e Zootecnia, 23(1), 131-138.

Rizato, C. A., Gusmão Filho, J. D., Sousa, B. M. L., Fagundes, J. L., Backes, A. A., Oliveira Junior, L. F. G., Nunes, T. E. S., Gomes, M. F., Vilas-Bôas, R. T., Santos Filho, J. R., Nascimento, C. S., \& Cruz, N. T. (2019). Produção de forragem e potencial de utilização do capim faixa-branca submetido a frequências de desfolhação. Arquivos Brasileiros de Medicina Veterinária e Zootecnia, 71(2), 613-622. DOI: http://dx.doi.org/10.1590/1678-4162-10302

Rodrigues, C. S., Nascimento Júnior, D., Detmann, E., Silva, S. C., Sousa, B. M. L., \& Silveira, M. C. T. (2012). Grupos funcionais de gramíneas forrageiras tropicais. Revista Brasileira de Zootecnia, 41(6), 1385-1393. DOI: https://doi.org/10.1590/S1516-35982012000600010

Sales, E. C. J., Saraiva, C. R. S., Reis, S. T., Rocha Júnior, V. R., Pires, D. A. A., \& Vitor, C. M. T. (2014). Morphogenesis and productivity of Pioneiro elephant grass under different residual heights and light interceptions. Acta Scientiarum. Animal Sciences, 36(2), 137-143. DOI: https://doi.org/10.4025/actascianimsci.v36i2.22220

Santos, R. M., Voltolini, T. V., Angelotti, F., Aidar, S. T., \& Chaves, A. R. M. (2014). Productive and morphogenetic responses of buffel grass at different air temperatures and $\mathrm{CO}_{2}$ concentrations. Revista Brasileira de Zootecnia, 43(8), 404-409. DOI: https://doi.org/10.1590/S1516-35982014000800002

Sbrissia, A. F., Duchini, P. G., Zanini, G. D., Santos, G. T., Padilha, D. A., \& Schmitt, D. (2018). Defoliation strategies in pastures submitted to intermittent stocking method: underlying mechanisms buffering forage accumulation over a range of grazing heights. Crop Science, 58(2), 945-954. DOI: https://doi.org/10.2135/cropsci2017.07.0447

Silva Neto, I. M., Souza, A. L., Zanine, A. M., Abreu, J. G., Ferreira, D. J., Toral, F. L. B., Alves, G. R., Castro, W. J. R., \& Pinho, R. M. A. (2019). Morphogenetic and structure characteristics of marandu grass subjected to grazing management strategies. Biological Rhythm Research, 51(6), 898-906. DOI: https://doi.org/10.1080/09291016.2018.1558738

Silva, J. T., Costa, K. A. P., Silva, V. C., Souza, W. F., Teixeira, D. A. A., \& Severiano, E. C. (2020a). Morphogenesis, structure, and dynamics of paiaguas palisadegrass tillering after intercroping with sorghum for the recovery of pasture in different forage systems. Bioscience Journal, 36(5), 1663-1675. DOI: http://dx.doi.org/10.14393/BJ-v36n5a2020-47747

Silva, S. C., \& Nascimento Júnior, D. (2007). Avanços na pesquisa com plantas forrageiras tropicais em pastagens: características morfofisiológicas e manejo do pastejo. Revista Brasileira de Zootecnia, 36(supl.), 122-138. DOI: https://doi.org/10.1590/S1516-35982007001000014

Silva, S. C., Bueno, A. A. O., Carnevalli, R. A., Silva, G. P., \& Chiavegato, M. B. (2020b). Nutritive value and morphological characteristics of Mombaça grass managed with different rotational grazing strategies. The Journal of Agricultural Science, 1-7. DOI: https:// doi.org/10.1017/S0021859620000052

Silva, S. C., Sbrissia, A. F., \& Pereira, L. E. T. (2015). Ecophysiology of C4 forage grasses - understanding plant growth for optimizing their use and management. Agriculture, 5(3), 598-625. DOI: https://doi.org/10.3390/agriculture5030598

Silveira, M. C. T., Nascimento Júnior, D., Silva, S. C., Euclides, V. P. B., Montagner, D. B., Sbrissia, A. F., Rodrigues, C. S., Sousa, B. M. L., Pena, K. S., \& Vilela, H. H. (2010). Morphogenetic and structural comparative characterization of tropical forage grass cultivars under free growth. Scientia Agricola, 67(2), 136-142. DOI: https://doi.org/10.1590/S0103-90162010000200002

Sousa, B. M. L.; Nascimento Júnior, D.; Rodrigues, C. S.; Monteiro, H. C. F.; Silva, S. C.; Fonseca, D. M. \& Sbrissia, A. F. (2011). Morphogenetic and structural characteristics of Xaraés palisadegrass submitted to cutting heights. Revista Brasileira de Zootecnia, 40(1), 53-59. DOI: http://dx.doi.org/10.1590/S1516-35982011000100008

Sousa, B. M. L., Rizato, C. A., Fagundes, J. L., Fontes, P. T. N., Backes, A. A., Oliveira Júnior, L. F. G., Cruz, N. T., \& Nascimento, C. S. D. (2019). Tillering dynamics of digit grass subjected to different defoliation frequencies. Pesquisa Agropecuária Brasileira, 54, e00668. DOI: https://doi.org/10.1590/s16783921.pab2019.v54.00668

Souza, J. P., Townsend, C. R., Araújo, S. R. C., \& Oliveira, G. A. (2020). Características morfogênicas, estruturais e agronômicas de gramíneas tropicais: uma revisão. Research, Society and Development, 9(8), e942986588. DOI: https://doi.org/10.33448/rsd-v9i8.6588

Taiz, L., Zeiger, E., Moller, I. M., \& Murphy, A. (2017). Fisiologia e Desenvolvimento Vegetal. $6^{\mathrm{a}}$ ed. Porto Alegre: Artmed, 848p.

Volenec, J. J., \& Nelson, C. J. (2020). Carbon Metabolism in Forage Plants. In: Moore, K. J.; Collins, M.; Nelson, C. J. \& Redfearn, D. D. (Eds.). Forage: The Science of Grassland Agriculture. Croydon: Willey Blackwell, cap. 4, p. 65-84.

Xing, Y., Jiang, W., He, X., Fiaz, S., Ahmad, S., Lei, X., Wang, W., Wang, Y., \& Wang, X. (2019). A review of nitrogen translocation and nitrogen-use efficiency. Journal of Plant Nutrition, 42(19), 2624-2641. DOI: https://doi.org/10.1080/01904167.2019.1656247

Xu, X., Dees, D., Dechesne, A., Huang, X. F., Visser, R. G., \& Trindade, L. M. (2017). Starch phosphorylation plays an important role in starch biosynthesis. Carbohydrate polymers, 157(10), 1628-1637. DOI: https://doi.org/10.1016/j.carbpol.2016.11.043

Yuan, J., Li, H., \& Yang, Y. (2020). The compensatory tillering in the forage grass Hordeum brevisubulatum after simulated grazing of different severity. Frontiers in Plant Science, 11, art. 792. DOI: https://dx.doi.org/10.3389\%2Ffpls.2020.00792 
Research, Society and Development, v. 10, n. 7, e5410716180, 2021

(CC BY 4.0) | ISSN 2525-3409 | DOI: http://dx.doi.org/10.33448/rsd-v10i7.16180

Zanine, A. M., Motta, G. P. R., Ferreira, D. J., Souza, A. L., Ribeiro, M. D., Geron, L. J. V., Fajardo, M., Sprunk, M., \& Pinho, R. M. A. (2019). Milk performance and grazing behavior of dairy cows in response to pasture allowance. Animal Production Science, 59(4), 749-756. DOI: https://doi.org/10.1071/AN17513

Zanini, G. D., Santos, G. T., \& Sbrissia, A. F. (2012). Frequencies and intensities of defoliation in Aruana Guineagrass swards: accumulation and morphological composition of forage. Revista Brasileira de Zootecnia, 41(4), 905-913. DOI: https://doi.org/10.1590/S1516-35982012000400011 